\title{
The Relationship Between Vitamin D and Infections Including COVID-19: Any Hopes?
}

\author{
Rbab Taha (D) \\ Shahd Abureesh (D) ${ }^{2}$ \\ Shuruq Alghamdi (iD ${ }^{2}$ \\ Rola Y Hassan (1D ${ }^{3}$ \\ Mohamed M Cheikh (iD) ${ }^{4,5}$ \\ Rania A Bagabir 6 \\ Hani Almoallim (D) ${ }^{2,7}$ \\ Altaf Abdulkhaliq $\mathbb{1 D}^{8}$ \\ 'Department of Transplant Infectious \\ Disease, University Health Network, \\ Toronto, Ontario, Canada; ${ }^{2}$ Department \\ of Medicine, Faculty of Medicine, Umm \\ Al-Qura University, Makkah, Saudi \\ Arabia; ${ }^{3}$ Department of Internal \\ Medicine, King Fahad Armed Forces \\ Hospital, Jeddah, Saudi Arabia; \\ ${ }^{4}$ Department of Internal Medicine, \\ Doctor Soliman Fakeeh Hospital, Jeddah, \\ Saudi Arabia; ${ }^{5}$ Department of Medicine, \\ Fakeeh College for Medical Sciences, \\ Jeddah, Saudi Arabia; ' ${ }^{6}$ epartment of \\ Immunology and Hematology, Faculty of \\ Medicine, Umm Al-Qura University, \\ Makkah, Saudi Arabia; ${ }^{7}$ Alzaidi Chair of \\ Research in Rheumatic Diseases, Faculty \\ of Medicine, Umm Al-Qura University, \\ Makkah, Saudi Arabia; ${ }^{8}$ Department of \\ Clinical Biochemistry, Faculty of \\ Medicine, Umm Al-Qura University, \\ Makkah, Saudi Arabia
}

Correspondence: Rola Y Hassan Email r.toufiq@hotmail.com

\begin{abstract}
Vitamin D is proposed to have a potential role in the pathogenicity, clinical presentation, prognosis, complications, and treatment of several diseases. In addition to its well-known role in calcium metabolism, vitamin D regulates both innate and adaptive immunity, and subsequently modulates the antiviral and antibacterial inflammatory immune responses. In view of the emerging coronavirus disease 2019 (COVID-19) pandemic, searching for potential therapeutic and protective strategies is of urgent interest, and vitamin $\mathrm{D}$ is one of the promising agents in this field. In this review, we present data from literature that supports the promising role of vitamin D in treatment and/or prevention of several infections including severe acute respiratory syndrome coronavirus 2 (SARS-CoV-2). This review summarizes vitamin D metabolism and its role in inflammation, thrombosis and immune regulation. It also reviews, in short, the role of vitamin D and the impact of its deficiency in several infections namely tuberculosis, influenza, human immunodeficiency virus (HIV), and SARS-CoV-2. Considering the roles of vitamin D on immune modulation, controlling of thrombosis, and attacking several microorganisms, the current review will elaborate on the association between these salient roles of vitamin $\mathrm{D}$ and the pathogenicity of various infectious agents including COVID-19. Consequently, the comprehensive finding of the current review shows a possible significant impact of vitamin D supplement as a hope in preventing, treating, and/or improving the progression of certain infections, specifically during the worldwide attempts to fight against the COVID-19 pandemic and minimize the severity of health complications encountered accordingly. In addition, avoiding a status of vitamin D deficiency to obtain its positive effects on the immune system and its protective mechanism during infections will be a general benefit overall.
\end{abstract}

Keywords: 1,25(OH)2D, 1,25-dihydroxyvitamin D, 25(OH)D, 25-hydroxyvitamin D, HIV, human immunodeficiency virus, SARS, COVID-19, severe acute respiratory syndrome, TB, tuberculosis, MTB, Mycobacterium tuberculosis, influenza

\section{Introduction}

Vitamin D is one of the essential micronutrients that has a significant role in modulation of both the innate and adaptive immune responses. ${ }^{1}$ During the coronavirus disease 2019 (COVID-19) era, there have been a considerable focus on the role of different vitamins and minerals in regulation of immunity, specifically vitamin D. ${ }^{2-4}$ Given the fact that vitamin D deficiency is common and widespread in all parts of the world with respect to ethnicities and geographic distribution, ${ }^{5-7}$ it is important to address the actual role of vitamin D in mediating the immune system response to infections including severe acute respiratory syndrome coronavirus 2 (SARS-CoV-2) infection. Thus, this review aimed at reviewing this interesting point of research. 
Vitamin D is a micronutrient that has some classical wellknown functions in maintaining and regulating calcium homeostasis and adequate bone mineralization. ${ }^{8}$ The two main sources of vitamin D are dermal synthesis under the effects of ultraviolet light from the sun and dietary sources, with dermal synthesis being the main source of the vast majority of vitamin D in blood. ${ }^{9}$ Vitamin D from both sources is biologically inactive and requires enzymatic conversion in liver and kidney to be an active metabolite. ${ }^{10}$ Vitamin D from either source is converted to 25-hydroxyvitamin $\mathrm{D}[25(\mathrm{OH}) \mathrm{D}]$, the main circulating form of vitamin $\mathrm{D}$, and then to 1,25 -dihydroxyvitamin $\mathrm{D}\left[1,25(\mathrm{OH})_{2} \mathrm{D}\right]$, the active form, by enzymes in the liver and kidney, respectively. ${ }^{11}$ The active form $\left[1,25(\mathrm{OH})_{2} \mathrm{D}\right]$ binds to the intracellular vitamin $\mathrm{D}$ receptors (VDR) to be activated within the targeted genes. ${ }^{10}$ In recent years, emphasis has been placed on the importance of vitamin $\mathrm{D}$ in areas beyond bone metabolism and calcium homeostasis, such as cardiovascular disease, infections, inflammation, and autoimmune diseases. ${ }^{10}$

The biological function of the active metabolite of vitamin D exceeds the classical effects on bone metabolism and calcium homeostasis to act as a pleiotropic endocrine hormone and influences many physiological processes. $^{12}$ Therefore, in recent years, emphasis has been placed on elaborating the important roles of vitamin $\mathrm{D}$ in areas beyond bone metabolism and calcium homeostasis including cell proliferation and differentiation, immune system, anti-aging process, and cardioprotective and neuroprotective effects. ${ }^{12}$

Vitamin D deficiency affects populations worldwide and has become a public health concern that is not limited to skeletal abnormalities but also chronic and metabolic diseases, immune conditions and cancer. ${ }^{13}$ Hypovitaminosis D affects approximately $13-50 \%$ of the world's population with higher prevalence in the Middle East, Asia, and Northern Europe. ${ }^{14}$

Vitamin D has a significant role in several diseases' pathogenicity, manifestations, prognosis, complications, and treatment. ${ }^{15}$ Vitamin D deficiency might increase mortality rates in patients with sepsis, as suggested by a recent systematic review. ${ }^{16}$ Some studies suggested associations between the risk of breast, prostate, and colon cancer and vitamin D deficiency. ${ }^{15}$ Emerging evidence points that vitamin D-mediated innate immunity is important in host defenses against respiratory tract pathogens, particularly through enhanced expression of the human cathelicidin antimicrobial peptide (hCAP-18). ${ }^{17}$ Moreover, observational studies suggest that vitamin $\mathrm{D}$ has some antiviral properties, and vitamin
D supplementation might decrease the risk of respiratory infections. ${ }^{2}$ These findings are simple but may play a significant role in our attempts to fight against the COVID19 pandemic and other infections by minimizing healthrelated complications through simple intervention. This review was constructed to elaborate on the relation between vitamin $\mathrm{D}$ deficiency and increased risk of infections including influenza virus, tuberculosis (TB), human immunodeficiency virus (HIV) and the recent pandemic due to severe acute respiratory syndrome coronavirus 2 (SARS-CoV-2). We aim to identify the potential hopes for vitamin $\mathrm{D}$ administration in preventing and/or managing these infections. For better understanding of such a relationship, it is essential to review vitamin D metabolism and the factors affecting it, the roles of vitamin D during inflammation, thrombosis and various infections, as well as the impact of vitamin D on the immune system. It is a meshed network that we are trying to describe and to connect the dots within. Hopefully, our better understanding might guide us to create ways to prevent and/or treat certain infections. However, large-scale, randomized interventional studies are still required to determine the role of vitamin D supplementation in preventing and treating certain infections.

\section{Vitamin D Metabolism}

\section{Sources, Synthesis, and Transport}

The obtained vitamin D (cholecalciferol) either from the skin after sun exposure, dietary intake, or supplements is biologically inactive and thus must undergo activation through two enzymatic hydroxylation reactions occurring in the liver and kidneys. ${ }^{2}$ It is carried by vitamin $\mathrm{D}$ binding protein (VDBP) and chylomicron to the liver, where it will undergo hydroxylation to form 25 hydroxycholecalciferol [25(OH)D] using 25-hydroxylase and members of the cytochrome P450 family, namely cytochrome P450 family 2 subfamily $\mathrm{R}$ member 1 (CYP2R1) and cytochrome P450 family 27 subfamily A member 1 (CYP27A1). ${ }^{18}$ Noting that most of the potential 25-hydroxylases are primarily expressed in the liver, and all are members of the cytochrome P450 family (CYP2C11, CYP2D25, CYP27A1, CYP3A4, CYP2R1, and CYP2J2/3). ${ }^{19-21}$ Among them, CYP27A1 and CYP2R1 are considered the most promising candidates for vitamin D 25-hydroxylation ${ }^{19-21}$. Following hydroxylation in the liver, 25(OH)D will be transported by VDBP to the kidneys, where it is converted by the action of $1 \alpha$, hydroxylase and CYP27B1 into the active 
form, $1 \alpha, 25$ dihydroxycholecalciferol $\left[1,25(\mathrm{OH})_{2} \mathrm{D}\right.$, or calcitriol]. ${ }^{18,22}$ A further hydroxylation by 24hydroxylase and CYP24A1 will inactivate 25(OH)2D and $1,25(\mathrm{OH})_{2} \mathrm{D}$ and convert them into inactive forms, $24,25(\mathrm{OH})_{2} \mathrm{D}$ and $1,24,25(\mathrm{OH}) 3 \mathrm{D}$, respectively (Figure 1). ${ }^{18,22}$

The vitamin D level in serum is closely regulated through feedback loops involving the actions of calcium, phosphorus, $1,25(\mathrm{OH})_{2} \mathrm{D}$, parathyroid hormone $(\mathrm{PTH})$, and fibroblast growth factor (FGF)-23. ${ }^{11,23}$ According to the guidelines of the American Endocrine Society, serum levels of 25(OH)D below $20 \mathrm{ng} / \mathrm{mL}(50 \mathrm{nmol} / \mathrm{L})$ are considered as vitamin $\mathrm{D}$ deficiency, while 25(OH)D serum levels between 21-29 $\mathrm{ng} / \mathrm{mL} \quad(52.5-72.5 \mathrm{nmol} / \mathrm{L})$ are defined as vitamin D insufficiency. ${ }^{24}$ Although $1 \alpha, 25(\mathrm{OH})_{2} \mathrm{D}$ is the most biologically active vitamin $\mathrm{D}$ metabolite that acts as a pleiotropic endocrine hormone and is responsible for many physiological processes $^{25}(25(\mathrm{OH}) \mathrm{D})$ or calcidiol, is considered the accepted biomarker for vitamin D3 status. ${ }^{26}$ This is because, like other hormones, $1,25(\mathrm{OH})_{2} \mathrm{D}$ circulates at picogram concentrations that are 1000 times less than those of the precursor $25(\mathrm{OH}) \mathrm{D}$, and its level is tightly regulated and stimulated by serum PTH, as well as low serum calcium and phosphorus levels but inhibited by circulating FGF-23 produced by osteocytes. $^{27}$ Thus, it would be difficult to estimate the actual low levels of $1,25(\mathrm{OH}) 2 \mathrm{D}$ in patients with vitamin $\mathrm{D}$ deficiency.

\section{Mechanism of Action on the Target Cells}

Vitamin D mediates its biological effects when the ligand of the active form, calcitriol, binds to its cognate nuclear vitamin D receptor (VDR), which belongs to a subfamily of nuclear receptors and the only protein binds $1,25(\mathrm{OH})_{2} \mathrm{D}$ effectively at sub-nanomolar concentrations. ${ }^{28}$ Upon interaction with its ligand, VDR heterodimerizes with the retinoic $\mathrm{X}$ receptor (RXR) and forms a heterodimer that acts as a transcription factor into the target cell. ${ }^{28}$ Consequently, binding of this heterodimer to the promotor region of vitamin D-responsive elements (VDREs) will regulate (induce or suppress) the expression of target genes in a given cell or at distant sites through interaction with additional co-regulators. ${ }^{29}$ As the VDR has been expressed on the vast majority of cell types including intestinal epithelium, renal tubules, parathyroid gland cells, skin (keratinocytes), mammary epithelium, pancreas (beta islet cells), pituitary gland, bone (osteoblasts and chondrocytes), immune cells (monocytes, macrophages, and T-lymphocytes), and germ tissues, this may explain the diverse actions of vitamin $\mathrm{D}$ on various tissues and systems in the body. $^{30}$

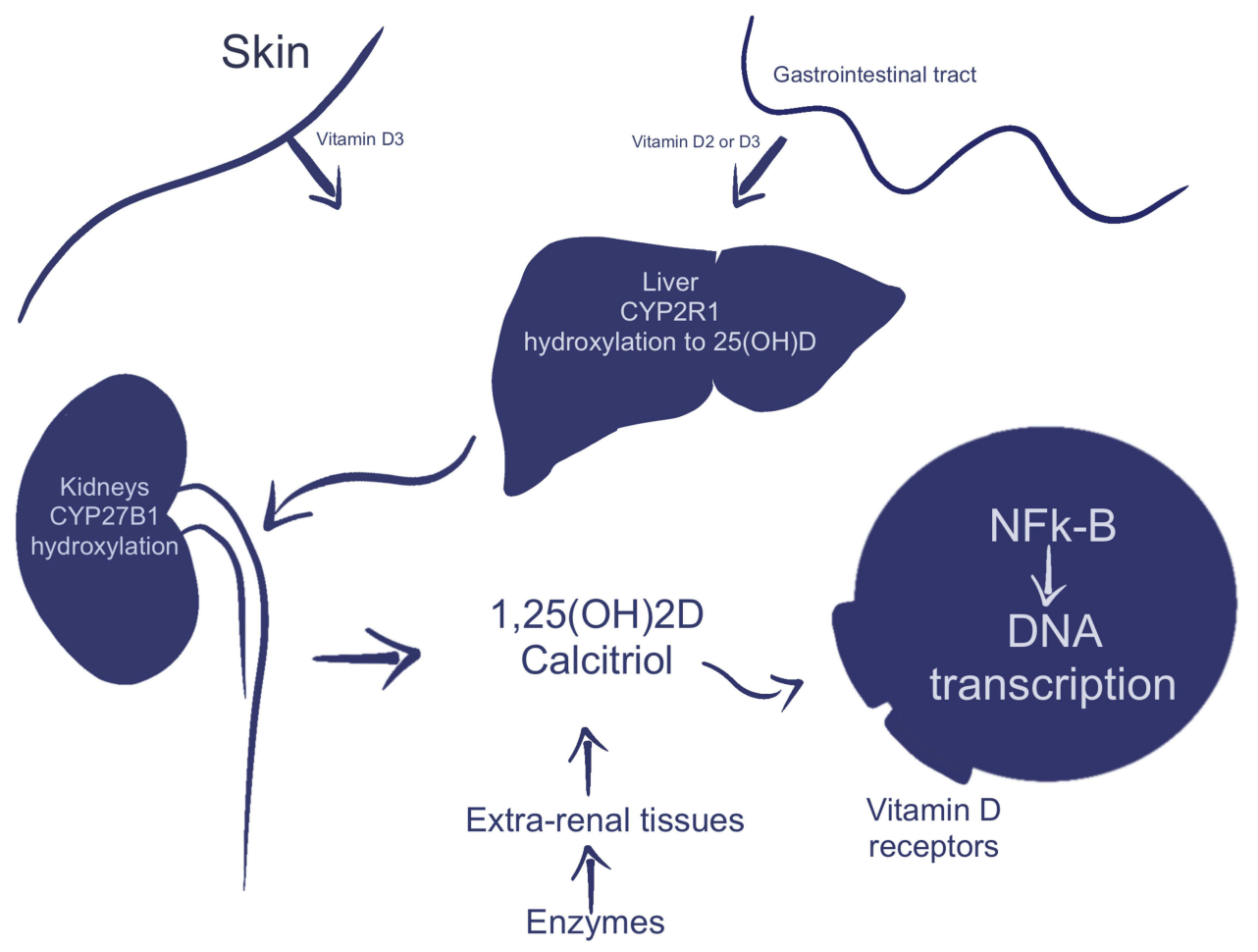

Figure I Synthesis and metabolism of vitamin D. Consecutive metabolic processes convert biologically inactive, parental vitamin D into active form. 


\section{Effects of Glutathione on Vitamin D Metabolism}

Glutathione (GSH), a major cellular thiol and antioxidant, plays a significant role in maintaining and regulating the thiolredox status of the cell. ${ }^{31}$ Given its high reactivity, the thiol group of its precursor - cysteine - has an important impact on multitudes of biological and cellular activities and functions, including cell differentiation, proliferation, and apoptosis. ${ }^{32,33}$ A depletion of GSH levels increases the oxidative stress and extensive carbonylation of proteins. ${ }^{34,35}$ These subsequently alter endogenous enzymes and proteins, resulting in protein function loss, and cell function impairment. ${ }^{36}$ Similar to vitamin D, albeit with a different mechanism, any disturbance in GSH homeostasis contributes to the etiology and/or progression of several medical conditions, including for instance cancer, cardiovascular, inflammatory, immune, metabolic, and neurodegenerative diseases. ${ }^{37}$

Previous studies reported a positive correlation between blood levels of $25(\mathrm{OH}) \mathrm{D}$ with glutathione and redox status in healthy adults and children; ${ }^{38,39}$ a recent study revealed that consumption of dietary antioxidants can raise the level of serum $25(\mathrm{OH}) \mathrm{D} .{ }^{40}$ Consistent with the latter findings, animal studies in rats have shown that low levels of GSH downregulate the VD-regulatory gene (VDBP/VD-25-hydroxylase (VDR) in the liver, kidneys, and muscle.

In contrast, supplementation of L-cysteine upregulates GSH and VDBP which subsequently increases the levels of serum $25(\mathrm{OH}) \mathrm{D} .^{41}$ On the other hand, Lei et al. asserted that vitamin D3 can also increase the expression of glutathione reductase and glutamate-cysteine modifier subunit, leading to an increase in the production of GSH, and thus resulting in a decrease of reactive oxygen species (ROS) and oxidative stress. ${ }^{42}$ Collectively, these findings support the hypothesis that vitamin D may have the ability to fight SARS-CoV-2 infections. $^{43}$

\section{Vitamin D and Immunomodulatory Effects}

The primary evidence that revealed the stimulant potential effect of vitamin D on innate immune system is when Grad (2004) used cod liver oil in treating tuberculosis. ${ }^{44}$ Subsequent enriched studies in this field reported that vitamin D has significant immunomodulatory function, specifically, augmenting the innate immune system and inhibiting the adaptive immune response. Most, if not all, cells of the immune system express VDR and CYP27B1, ${ }^{45}$ as well as CYP2R1, and thus they can produce $1,25(\mathrm{OH})_{2} \mathrm{D}$ from circulating vitamin $\mathrm{D} .{ }^{46}$ Unlike the kidneys, regulation of CYP27B1 in immune cells lack the hormonal regulation of $\mathrm{PTH}$ and FGF23, its product $1,25(\mathrm{OH})_{2} \mathrm{D}$, calcium and phosphate levels. ${ }^{47}$ However, in these immune cells, CYP27B1 is stimulated by cytokines such as tumor necrosis factor (TNF)-alpha and interferon (IFN). ${ }^{47,48}$ Thus, subsequent activation of these immune cells in diseases such as lymphomas may cause hypercalcemia with elevated $1,25(\mathrm{OH})_{2} \mathrm{D}$ levels. ${ }^{47,48}$

\section{Innate Immunity}

Innate immunity is considered the first defense mechanism against invading microorganisms including bacteria, viruses, fungi and protozoa. This immune system initially recognizes a microorganism or its products via pathogen-recognition receptors (PRR) which then trigger a cascade of events that will end with the removal and/or destruction of the invading agents. ${ }^{49}$ Upon invasion with infectious organisms, Toll-like receptors (TLRs), sub-members of PRR, are activated and consequently stimulate the TLR-expressing cell to release cytokines and various antimicrobial peptides (AMPs). ${ }^{50}$ Several studies had revealed that vitamin D and downstream receptor signaling play salient roles in mediating macrophages and other immune cells to enhance host antimicrobial defense via regulating their immune and inflammatory activities. ${ }^{50,51}$ Among these studies, researchers showed that stimulation of TLR 2/1 in macrophages ${ }^{50}$ or TLR2 in keratinocytes ${ }^{50}$ increased the expression of CYP27B1 and VDR. In the presence of adequate substrate $(25(\mathrm{OH}) \mathrm{D})$ level, these cells had produced $1,25(\mathrm{OH})_{2} \mathrm{D}$ (the active form of vitamin $\mathrm{D}$ ) that in turn induced the release of AMPs such as cathelicidin and defensins (Figure 2A). ${ }^{50,51}$ The TLR-CYP27B1-VDR-cathelicidin pathway is the demonstrated mechanism by which $1,25(\mathrm{OH})_{2} \mathrm{D}$ was capable of inhibiting the growth of $M$ tuberculosis in vitro, ${ }^{52}$ and is thus considered as a crucial immune modulator that impacts innate and adaptive immunity. Accordingly, this may explain the susceptibility of vitamin Ddeficient subjects to having tuberculosis. ${ }^{53}$ Another clinical study revealed that patients with atopic dermatitis, who are susceptible to microbial infection due to the decreased production of cathelicidin and other AMPs by IL- 4 and IL-13, ${ }^{54}$ can be improved by vitamin D supplementation. However, unfortunately the beneficial outcome of vitamin D supplementation for treating M. tuberculosis in vitamin D-deficient patients was not successful universally. ${ }^{55,56}$

\section{Adaptive Immunity}

The adaptive immune system is the second defense mechanism against invading microorganisms which mediates an 

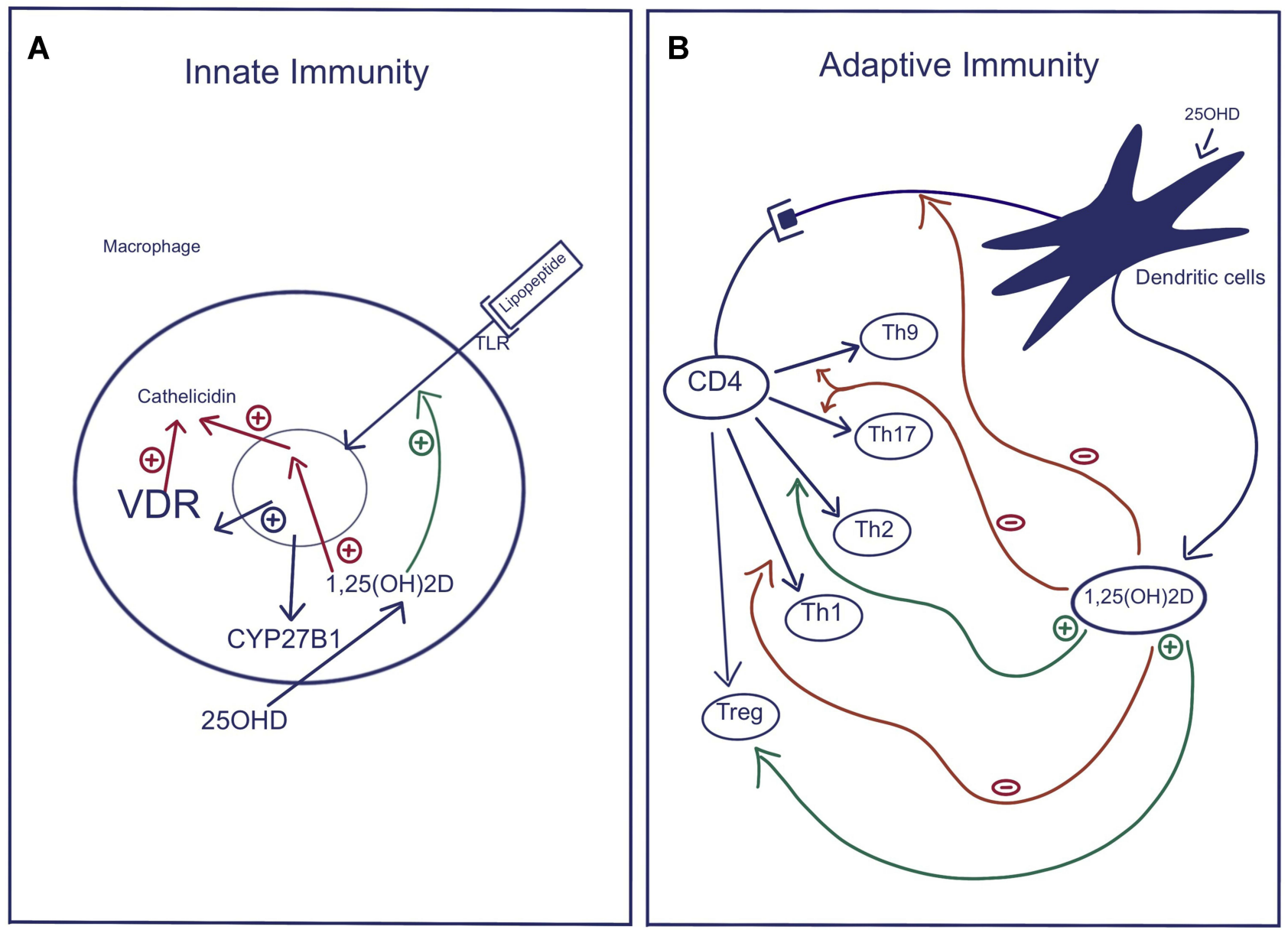

Figure 2 Role of Vitamin D in regulation of the innate and adaptive Immune Pathways. (A) Innate immunity: Activation of selective Toll-like receptors (TLRI/2) by products of infectious organisms results in the induction of both VDR and CYP27BI. With adequate substrate $25(\mathrm{OH}) \mathrm{D}, 1,25(\mathrm{OH})_{2} \mathrm{D}$ is produced that, in combination with VDR, induces the formation of antimicrobial peptides such as cathelicidin, which are capable of killing intracellular organisms. (B) Adaptive immunity: I,25(OH) $2 \mathrm{D}$, which is produced by dendritic cells, decreases the maturation and antigen presenting ability of dendritic cells and alters the profile of $\mathrm{T}$ helper cells that differentiate from the activated CD4 parent cell, precisely, reduces the formation of ThI, ThI7, and Th9 cells, while promoting the differentiation of Th2 and Treg cells. The result is overall suppression of the adaptive immune pathway.

antigen-specific immune response through antigen presentation cells (APC), namely dendritic cells (DCs), and the antigen recognition cells, $\mathrm{T}$ and $\mathrm{B}$ lymphocytes. Therefore, activation of these APC causes the production of various cytokines and antibodies and induces cell killing. The $\mathrm{T}$ lymphocytes ( $\mathrm{T}$ cells) consist of various subgroups of cells, for instance CD4 helper T-cells (Th cells), CD4 regulatory T-cells (Treg), CD8 cytotoxic T-cells, natural killer (NK) cells, and memory cells. ${ }^{57}$ Vitamin D can exert either a direct effect on lymphocytes via VDR signaling or an indirect effect through paracrine signaling on APC. Vitamin D decreases the maturation of DCs and their ability to present antigens and alters the profile of $\mathrm{T}$ helper cells (Th1, Th2, Th9, Th17) and Treg cells. ${ }^{57}$ Previous studies reported that vitamin D inhibited Th1 cell function which in turn decreased the production of TNF-alpha, IL-2, granulocyte macrophage colony-stimulating factor (GMCSF) and IFN-beta. ${ }^{58,59}$ On the other hand, vitamin $\mathrm{D}$ enhances the differentiation and proliferation of Th2 and Treg cells, and thus stimulates the production of their antiinflammatory cytokines including IL-4, IL-5, and IL-10 that further suppresses the development of Th1, Th17, and Th9 cells, producing immune tolerance. ${ }^{60}$ Accordingly, vitamin D suppresses T-cell-mediated and inappropriate inflammation with the net result being the overall suppression of the adaptive immune response (Figure $2 \mathrm{~B}$ ). ${ }^{57}$

The observed shift from a Th1 to a Th2 profile was assumed to be a significant mechanism by which vitamin $\mathrm{D}$ could be advantageous in autoimmune diseases. ${ }^{61}$ Moreover, a high level of VDR expression was found on cytotoxic $\mathrm{T}$ cells ${ }^{62}$ that were suggested to have a role in autoimmune diseases such as multiple sclerosis. ${ }^{63}$ Within 
this context, several clinical studies showed an inverse correlation between 25(OH)D3 levels and/or vitamin $\mathrm{D}$ intake and the occurrence of a number of autoimmune diseases, for instance, multiple sclerosis, type 1 diabetes, rheumatoid arthritis, gravis thyroiditis, asthma and atopic dermatitis. A review of a meta-analysis of four trials showed that vitamin D supplementation may help ameliorate the severity of atopic dermatitis. Data from an Italian study have shown a possible link between vitamin D insufficiency and a higher frequency of SLE flares. ${ }^{64}$ A correlation between flare severity and an overall more active disease was also suggested by a Chinese study. ${ }^{65}$ On the contrary, other clinical studies in rheumatoid arthritis did not confirm the suppressive effects of vitamin D on Th1 cells and cytokines production. ${ }^{66}$

With regards to $\mathrm{B}$ cells, Chen et al. reported that B cells expressed very low levels of VDR, which could be upregulated upon activation with various stimuli. ${ }^{67}$ Subsequent evidence confirmed that vitamin $\mathrm{D}$ has a direct effect on $\mathrm{B}$ cells via inhibiting memory and plasma-cell generation and proliferation, as well as enhancing the apoptosis of immunoglobulin-producing B cells causing inhibition of immunoglobulin production. ${ }^{18,58,62,68}$ These findings were consistent with previous in vitro studies that revealed that vitamin D3 treatment inhibited the secretion of immunoglobulins $\operatorname{IgG}$ and $\operatorname{IgM}$ by activated B cells. ${ }^{69}$ The impact of vitamin D on B cells is clinically valuable in autoimmune diseases due to the major role of B cells which produce autoreactive antibodies in the pathophysiology of autoimmunity.

Taken together, vitamin D supplementation can be considered as a safe and supportable therapy for these diseases; however, it necessitates larger-scale studies over a longer duration of therapy to confirm this assumption.

\section{Vitamin D and Renin-Angiotensin- System}

Renin-Angiotensin-System (RAS) has an important role in controlling vascular resistance and extracellular fluid homeostasis. $^{70}$ Synthesis and secretion of renin (as the rate limiting step) is stimulated by reduction in fluid volume, perfusion pressure, and salt concentration (Figure 3). ${ }^{70}$ Renin is formed in the kidneys and is responsible to cleave the angiotensinogen secreted from the liver to the inactive form angiotensin $\mathrm{I}^{70}$ On the surface of endothelial cells, the latter peptide is cleaved by the angiotensin-converting-enzyme (ACE) into active angiotensin II, which will bind to two receptors, Angiotensin Receptor 1 or 2 [AT1R or AT2R] to exert its effects. ${ }^{70}$ Upon binding to AT1R, Angiotensin II causes the release of catecholamine and vasoconstriction, and exerts pro-inflammatory and pro-oxidative effects. The level of Angiotensin II regulates renin formation, which is abolished with a higher amount of Angiotensin II via an AT1R mediated effect. ${ }^{71}$ In contrast, it is stimulated by lower levels of Angiotensin II, Angiotensin II converting enzyme inhibitors (ACEI), or Angiotensin II receptor blockers $(\mathrm{ARB}) .^{71}$

A novel homologue of ACE, ACE2, has been found to cleave Angiotensin I to Angiotensin 1-9 that have cardioprotective effects via AT2R, and Angiotensin II to Angiotensin 1-7 that acts via Mas Oncogene (Figure 3). This cleavage makes Angiotensin I and II less available for the ACE/Angiotensin II/AT1 axis and thus counterbalances the pathological effect of Angiotensin, namely the "overstimulation" of the RAS and its pathological consequences including inflammation, vasoconstriction, hypertrophy and fibrosis ${ }^{21,72}$ (Figure 3). In addition, ACE2 can reinforce the ACE2/Angiotensin 1-7/Mas axis, which decreases the proinflammatory RAS activation. The ACE2 is expressed in various organs' tissues including kidney, lung, cardiomyocytes, cardiac fibroblasts, vascular smooth muscle and endothelial cells. ${ }^{21,72}$

It has been reported that individuals with low vitamin D levels showed increased RAS activity, and Angiotensin II concentrations, ${ }^{73,74}$ and vice versa, higher vitamin D levels reflect decreasing RAS activity. ${ }^{75}$ These findings were explained by cellular and molecular studies that revealed vitamin $\mathrm{D}$ is a negative regulator of RAS via suppressing transcriptional activity on the renin gene promoter, a process independent from Angiotensin II feedback regulation. ${ }^{76,77}$ Other studies found that vitamin D exerts pronounced impacts on ACE2/Angiotensin (17)/Mas axis with enhanced expression of ACE2, ${ }^{78}$ as well as being able to effectively inhibit NFאB activation. ${ }^{79}$

These findings were consistent with a number of clinical studies, of which, one study revealed a significant decrease in plasma renin activity and concentration in individuals who received $2000 \mathrm{IU}$ vitamin D3, ${ }^{80}$ while another study showed a correlation between higher circulating Angiotensin II levels and hypovitaminosis D status. ${ }^{81}$ A further study elaborated on the effect of vitamin D supplementation (4000 IU/day) over 36 months. ${ }^{82}$ Although initial results showed no relationship between the increase in blood levels of vitamin D and various parameters of the RAS (renin, aldosterone), results 


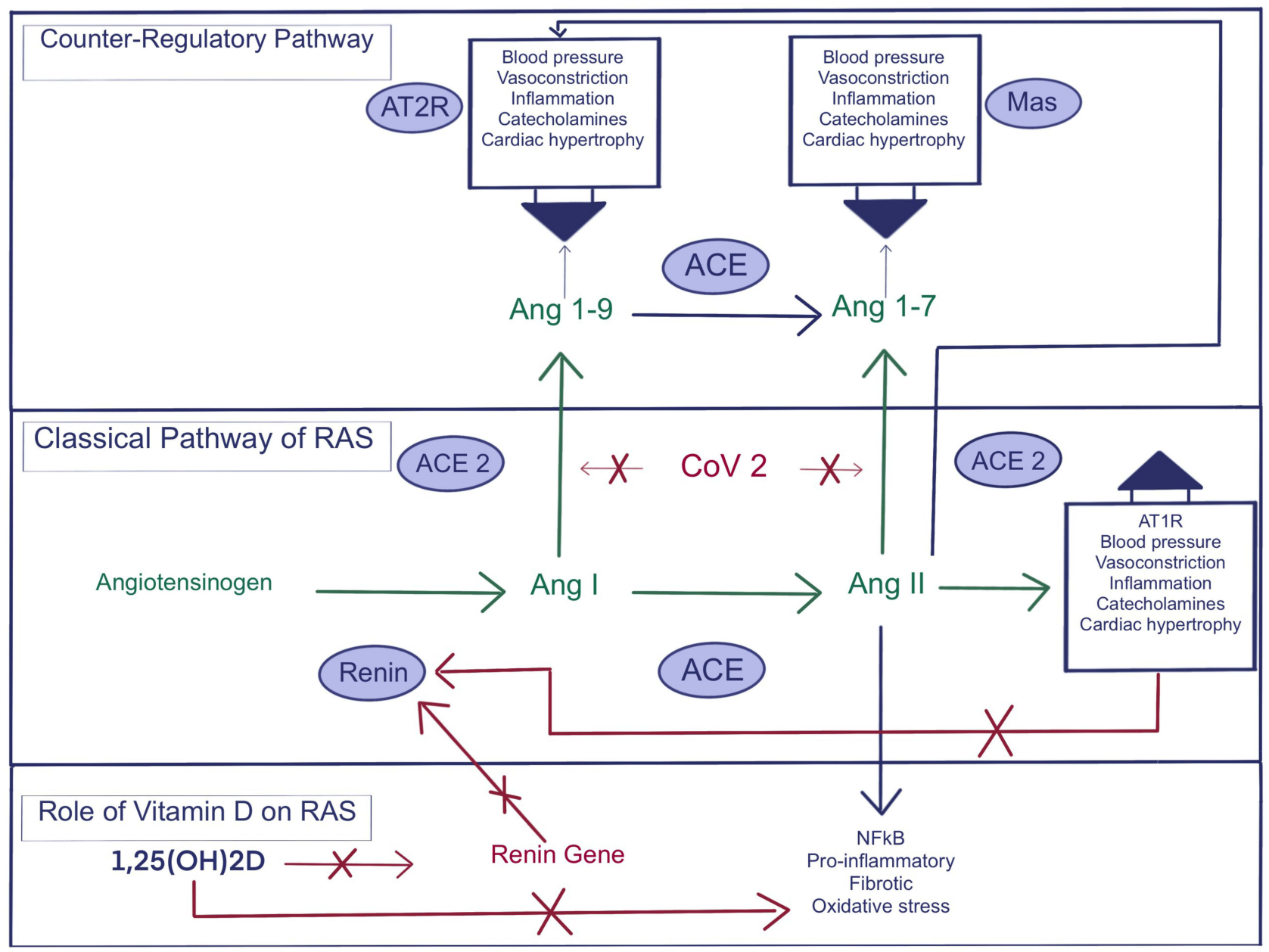

Figure 3 The Classical RAS Pathway, The Counterbalance Regulatory Pathway, and the role of vitamin D in controlling the RAS pathway. Note: Some of the data is from Biesalski. ${ }^{70}$

from a subgroup with vitamin $\mathrm{D}$ deficiency revealed a decrease in renin concentration with the increasing level of vitamin D. ${ }^{82}$

In the classical RAS pathway, renin induces cleavage of Angiotensinogen to Angiotensin I, which is converted to Angiotensin II via Angiotensin converting enzyme (ACE). Angiotensin II activates the (AT1R), which results in an increase of blood pressure with further effects on the vascular system. In addition, Angiotensin II suppresses renin synthesis via AT1R. The counterbalance regulatory pathway is activated through cleavage of Angiotensin I to Ang1-9 via ACE2 or AT2R activation, or Angiotensin II to Ang1-7 which counter regulates via Mas receptor. This helps the RAS to stay within a homeostatic balance by controlling the RAS activity. If the counter regulatory pathway of RAS is disrupted, this may lead to higher level of Angiotensin II and renin synthesis. However, vitamin $\mathrm{D}\left(1,25(\mathrm{OH})_{2} \mathrm{D}\right)$ can counteract the RAS misbalance via negative expression of the renin gene, which results in lower renin synthesis independent from Angiotensin II. In addition, vitamin D can effectively inhibit NFкB activation.

\section{Vitamin D and Inflammation}

The role of vitamin D has been explored over the recent decades and there is compelling evidence for an epidemiological association between poor vitamin D status and a variety of infectious diseases. ${ }^{15}$ Infection is involved in many inflammatory and chronic diseases. ${ }^{83}$ Based on recent studies, vitamin D status may have a crucial role in regulating immune response. ${ }^{1,83-85}$ The immunomodulatory effects of vitamin D also possibly explain the epidemiological associations between a large number of autoimmune diseases and vitamin D status. ${ }^{86}$ 
In studies addressing the pathogenesis of infections, intracellular bacteria were found to disrupt vitamin $\mathrm{D}$ and regulation of the immune system, resulting in persistent infection and chronic inflammation. ${ }^{87}$ Vitamin D was also reported to reduce the cytokine storm that occurs in response to some infections. ${ }^{86}$ This might explain the severe immune reaction in some infectious diseases and the storm of cytokines, which varies between patients, based on multiple factors including vitamin D status. ${ }^{87}$ In a study focusing on the possible impact of vitamin D status on COVID-19, vitamin D was reported to reduce the cytokine storm and consequently reduce mortality among patients with severe COVID-19. These patients were found to have notable elevation of inflammatory cytokines such as interleukin 2R (IL-2R), interleukin 6 (IL-6), granulocyte colony-stimulating factor (GCSF), macrophage chemotactic protein-1 (MCP1), macrophage inflammatory protein (MIP)1A, TNF- $\alpha$ and anti-inflammatory compounds such as C-reactive protein (CRP). ${ }^{86}$

Calcitriol, the active form of vitamin $\mathrm{D}$, controls the gene expression of VDR which can reduce the inflammatory markers. ${ }^{86}$ Cholecalciferol (vitamin $\mathrm{D}$ analog) reduces levels of pro-inflammatory cytokines such as TNF- $\alpha$ and IFN- $\gamma$, and increases anti-inflammatory cytokines such as IL-10. ${ }^{86}$ In addition, vitamin D blocks TNF- $\alpha$ in mycobacteria-infected macrophages and peripheral blood mononuclear cells from pulmonary TB patients, ${ }^{88,89}$ and hence vitamin $\mathrm{D}$ has long been used in the treatment of mycobacterial infections. ${ }^{90}$

It is known that viral infection induces massive ROS production and oxidative damage. ${ }^{91}$ However, GSH can protect the body from the harmful effects of oxidative damage and excess reactive oxygen radicals. ${ }^{31}$ In addition, GSH is essential to maintaining the vitamin D-metabolism genes as well as the circulating levels of $25(\mathrm{OH}) \mathrm{D} .{ }^{40,41} \mathrm{In}$ a placebo-controlled study, vitamin $\mathrm{D}$ supplementation was found to decrease the inflammatory cytokine TNF- $\alpha$, IL-6 and CRP which are involved in oxidative stress and inflammation. ${ }^{88}$

\section{Vitamin D and Thrombosis}

The severity of a COVID-19 infection is specified by the presence of acute respiratory distress syndrome, myocarditis, microvascular thrombosis and/or cytokine storms, all of which suggest an underlying severe inflammation. ${ }^{92}$ Along with the previously discussed vitamin D role in regulation of inflammation, recent evidence suggests its involvement in thrombotic events associated with severe inflammation. ${ }^{92}$ Vitamin $\mathrm{D}$ deficiency was found to be associated with the rise of thrombotic episodes, which are frequently spotted in patients with COVID-19 and certain other infections. ${ }^{92}$ Systemic or localized infections significantly increase the risk of thrombosis by 2 to 20 times and are independent risk factors for venous thromboembolic (VTE) diseases such as deep vein thrombosis (DVT)/pulmonary embolism (PE), as well as cardiovascular disease (CVD) (e.g. myocardial infarction) and cerebrovascular events (stroke). ${ }^{93}$

In the literature, there has been an interesting discussion about the probable relationship between infection-induced thrombosis and pre-existing risk factors, such as smoking, lipid levels, and possibly vitamin D status. ${ }^{94}$ These factors can directly influence pathogen-driven thrombosis or alternatively the infection promotes the risk of thrombosis through these factors. ${ }^{94}$ Moreover, exacerbations of CVD, including acute myocardial infarction, has been observed in some infections caused by Neisseria meningitidis, Staphylococcus aureus and recently in COVID-19 infection. ${ }^{95}$ This adds to the complexity of this kind of relationship between vitamin D and thrombosis through infection. Several studies suggested that there is a direct correlation between vitamin D deficiency and thrombosis risk. ${ }^{94}$ In a prospective study evaluating the risk factors for VTE, actively sun-exposed women were found to have a $30 \%$ lower risk of developing VTE, and the risk was $50 \%$ higher in winter months. ${ }^{96}$ The authors attributed their results to the potential role of vitamin $\mathrm{D}$ in reducing thrombotic events. ${ }^{96}$ In a randomized control trial of 36,282 postmenopausal women, low doses of vitamin D supplements were found to reduce the mortality rates due to stroke and cancer. ${ }^{97}$ In COVID-19 cases, venous and arterial thrombo-embolic events occur in approximately $28 \%$ of cases and are an indicator of severity. ${ }^{98,99}$ Vitamin D deficiency was prevalent in about $70 \%$ of such severe hospitalized cases of COVID-19 infection. ${ }^{99}$ Based on these findings, the role of vitamin D supplements in preventing or alleviating the incidence of thrombosis in COVID-19 infection has gained considerable attention from researchers during the past few months. ${ }^{100}$ However, no solid data exist about whether routine administration of vitamin D supplements would be beneficial in severe COVID-19 infected patients or not.

The actual mechanism of vitamin D in reducing thrombotic events remains elusive. One of the proposed theories suggests that vitamin D exerts an anticoagulant effect by up-regulating the expression of an anticoagulant glycoprotein, thrombomodulin, and down-regulating the expression of critical coagulation factors. ${ }^{101}$ Another proposed theory suggests that vitamin D reduces thrombosis via its impact on the RAS. ${ }^{76}$ 
Vitamin D negatively modulates RAS and inhibits renin expression and synthesis ${ }^{82,102}$ (Figure 3). This reduces the negative impact of RAS on blood pressure and vasculature. ${ }^{103}$ Moreover, vitamin D increases the expression of ACE2 which is a part of the RAS that serves as an important entry point for SARS-CoV-2. ${ }^{103}$ When SARS-CoV-2 enters the cell, it inhibits the expression of ACE2 and subsequently causes lung damage and pneumonia. ${ }^{103}$ Vitamin D-mediated induction of ACE2 receptors is, therefore, a proposed protective mechanism against severe lung injury in the context of COVID-19.76,102 This also might give hope on new modalities in preventing VTE diseases.

\section{Vitamin D and Influenza}

Influenza infection is caused by enveloped viruses that affect the respiratory tract by either direct viral infections or by damaging the immune response. ${ }^{2}$ The current estimated mortality rate associated with influenza is $4.0-8.8$ per 100,000 people per year. ${ }^{2}$ Seasonal influenza has been found to generally peak in winter; and such seasonal variation is attributed to decreased ultraviolet light exposure, low temperature, and humidity. In these environmental circumstances, the influenza viruses survive longer outside the body. ${ }^{2}$

Edgar Hope-Simpson was the first to suggest that the seasonal variation of influenza relies on periods of less sunlight. ${ }^{103}$ He hypothesized that low ultraviolet light doses are related to a decrease in the level of the active form of vitamin $\mathrm{D}\left(1,25(\mathrm{OH})_{2} \mathrm{D}\right) .{ }^{103}$ Later on, several studies demonstrated a positive correlation between vitamin D deficiency and increased risk for influenza infection. ${ }^{104,105}$ Zykov and Sosunov found that influenza virus is more likely to be shed in December $(40 \%)$ than in September $(16 \%)$ when they attempted to recover the virus $48-72 \mathrm{~h}$ after inoculation, and the amount of virus shed was substantially lower in summer than in winter which can be attributed to certain factors such as UVB light exposure and vitamin D. ${ }^{106}$ Furthermore, vitamin $\mathrm{D}$ has been found to have a preventive effect against influenza virus infection via enhancing the innate immunity by upregulation and production of antimicrobials such as defensin in primary human monocytes, neutrophils, natural killer cells and in peripheral cell lining the respiratory tract. ${ }^{104,106}$ Defensin prevents influenza virus infection by blocking viral hemagglutinin-mediated membrane fusion. ${ }^{91}$ This preventive effect of vitamin D supplements against influenza was also demonstrated in children. ${ }^{91}$

In addition to its impact on antimicrobials upregulation, vitamin $\mathrm{D}$ was also reported to reduce inflammation via controlling cytokine release as aforementioned. This also explains its potential role in influenza and other infections. ${ }^{91}$ Vitamin D concentration of $38 \mathrm{ng} / \mathrm{mL}$ or more showed a double reduction in the risk of developing acute respiratory tract infections (ARTI) and a substantial decrease in the number of illness days. ${ }^{2}$ Moreover, evidence of a dramatic vitamin D preventive effect from a randomized controlled trial (RCT) was presented in 2008 by Aloia and Li-Ng. ${ }^{107}$ In this trial, 104 postmenopausal African American women were given vitamin D and 104 were given placebo. Women who received vitamin $\mathrm{D}$ were three times less likely to experience cold and flu symptoms. ${ }^{107}$ Martineau et al., in their systematic review and meta-analysis of 26 eligible randomized controlled trials, reported that vitamin D supplementation significantly decreased the risk of ARTI. ${ }^{105}$ Pharmacological doses of vitamin D (1000-2000 IU/Kg per day) for several days were also reported to be helpful in the treatment of winter-peak viral respiratory infections. ${ }^{108}$ However, this protective effect of vitamin D is not consistent in literature. For instance, vitamin D was not found to reduce influenza in children and adolescents in one study, but it could reduce non-influenza respiratory infections. ${ }^{106}$ Thus, there is still a need for properly conducted large, prospective randomized controlled trials on different population ages and characteristics to address the actual role of vitamin D in preventing ARTI.

In summary, vitamin D-mediated stimulation of the development of virucidal antimicrobial peptides and suppression of the development of cytokines provides a promising role in prevention of influenza. However, data from the literature are still lacking to develop solid guidelines in various clinical situations e.g. the role of checking on vitamin D levels and/or considering administration of vitamin D supplementation for populations at risk for influenza (e.g. elderly individuals) before and during winter months. Valid scientific research is required to provide a practice recommendation for these situations.

\section{Vitamin D and Tuberculosis}

Tuberculosis (TB) remains a common major cause of ill health worldwide especially in the context of the COVID19 pandemic. ${ }^{109}$ Based on WHO reports, the incidence rate is falling, but not fast enough to reach the 2020 milestone of a 20\% reduction between 2015-2020. ${ }^{109}$ Mycobacterium tuberculosis (MTB) has complex cell membranes that contain methyl branched-chain fatty acids which allow them to escape immune mechanisms and, therefore, can survive for long periods in the host cells. ${ }^{110}$ MTB components expressed on cell surfaces have 
complex interactions with various members of the toll-like receptor (TLR) family that reside on macrophages. ${ }^{10}$ Such complex interaction leads to disease complications by other co-morbidities and co-infection (e.g. HIV) making the treatment more challenging. ${ }^{111}$ The long duration needed for treatment and the significant side effects of anti-TB treatments raise the need of finding protective methods (e.g. infection control and vitamin supplementations) to overcome these issues. ${ }^{112}$

Vitamin D is a possible novel approach to alleviate TB. ${ }^{112,113}$ As vitamin D is characterized by immunomodulatory effects against infections, the hypothesis regarding its effectiveness as a protective drug to prevent progression of TB has been evaluated in recent studies. Nonoaham et al., in their systematic review and metaanalysis conducted in 2008 reviewing the role of vitamin $\mathrm{D}$ in TB, concluded that vitamin $\mathrm{D}$ levels were significantly lower in TB patients compared with controls. ${ }^{114}$ Moreover, the TB clinical characteristics were reported to be related to VDR genotypes. ${ }^{115}$ A recent review reported that vitamin $\mathrm{D}$ supplementation inhibited the growth and replications of MTB through the production of cathelicidin. ${ }^{116}$ The synthesis of $1,25(\mathrm{OH})_{2} \mathrm{D}$ was found to aid VDR-mediated transactivation of the antimicrobial peptide cathelicidin and subsequent killing of intracellular MTB. ${ }^{116}$ In a cohort of TB patients and their contacts $(\mathrm{N}=$ 129) in Pakistan, it was found that $79 \%$ of patients with active TB disease had low vitamin D levels. ${ }^{117}$ Additionally, low vitamin D levels were associated with extended risk for progression to TB. ${ }^{117}$ Similar results were reported in a study of vitamin $\mathrm{D}$ levels among $\mathrm{TB}$ patients in Korea. ${ }^{83}$ Patients with TB were found to have a higher prevalence of vitamin D deficiency than control group. In this study, almost half of the patients (i.e. 48 patients, 51.1\%) had severe vitamin D deficiency ( $\leqslant 10 \mathrm{ng} /$ $\mathrm{mL})$, whilst only $8.2 \%(\mathrm{~N}=23)$ of the control group had severe deficiency. ${ }^{83}$ The differences between the two groups were statistically significant. ${ }^{83}$ Gouet al. demonstrated that vitamin D levels were lower in children with TB. ${ }^{118}$ Likewise, Aibana et al. illustrated that low vitamin $D$ levels were associated with increased risk of progression to TB disease in a dose-dependent manner and that the risk of TB disease is highest among HIV-positive individuals with severe vitamin $\mathrm{D}$ deficiency. ${ }^{119}$ One of the randomized controlled trials reported that treatment of TB through adjunct therapy with phenylbutyrate and vitamin D3 as a standard short-course therapy resulted in increased expression of cathelicidin LL-37 which enhanced intracellular killing of MTB in macrophages ex vivo. ${ }^{112}$ Based on those findings, vitamin $\mathrm{D}$ deficiency is proposed by many researchers to be a familiar risk factor in TB patients. ${ }^{120}$

Despite the noted positive association between vitamin $\mathrm{D}$ deficiency and progression to active TB in multiple clinical trials, the data were not consistent in several other studies. For instance, one trial suggested that weekly oral vitamin D supplementation with 14,000 IU was effective in safely elevating $25(\mathrm{OH}) \mathrm{D}$ levels in a huge population of vitamin $\mathrm{D}$ deficient children but did not result in decreasing the risk of TB in comparison with placebo. ${ }^{121}$ Similarly, a recent review of randomized controlled trials investigating the effects of adjunctive vitamin D supplements in TB patients claimed no clear clinical benefits observed although some trials showed that protective efficacy of this intervention is most remarkable when vitamin $\mathrm{D}$ is given in daily or weekly doses to individuals with low 25(OH)D levels at baseline. ${ }^{122}$ Also, another randomized controlled trial suggested that neither oral vitamin D nor L-arginine had discernible effects on clinical outcomes of pulmonary TB. ${ }^{123}$ Though all these trials showed negative outcomes with regard to the role of vitamin D in TB infection, most of these trials have multiple limitations, specifically during the evaluation process in measurement of vitamin D levels and in diagnostic tests for TB. Therefore, future randomized controlled trials need to legitimize their quality and design to elaborate efficiency of vitamin D supplementation in TB prevention and management. Such evidence would require a demonstration of the feasibility and cost-effectiveness of a screening strategy, as well as benefits in terms of health outcomes. However, in 2011 the Endocrine Society Clinical Practice Guidelines had recommended that measurements are imperative in groups at higher risk for vitamin D deficiency, such as in patients suffering from granuloma-forming disorders including $\mathrm{TB}^{24}$

\section{Vitamin D and Human Immunodeficiency Virus (HIV)}

$\mathrm{HIV}$ is a global health problem that affects 75 million people and has caused about 32 million deaths worldwide. ${ }^{124}$ HIV-infected people seem to have higher morbidity rates in comparison with the healthy population due to both chronic adverse drug reactions and to agerelated morbidities including cardiovascular, metabolic disease, neurocognitive disorders, renal and bone diseases, 
and cancer. These chronic diseases appear to take place earlier in HIV patients compared with the general population due to multiple causes including continuous inflammation, nutritional deficiency and HIV infection itself. $^{124,125}$

Several studies suggest that low $1,25(\mathrm{OH})_{2} \mathrm{D}$ levels could be responsible for an increased morbidity and mortality in HIV-infected people. ${ }^{124,126}$ Mansueto et al. showed that the prevalence of vitamin $\mathrm{D}$ deficiency ranges from $70-85 \%$ in HIV-infected patients. ${ }^{124}$ Vitamin $\mathrm{D}$ deficiency is frequent in persons infected with HIV, even on successfully combined antiretroviral therapy (cART). ${ }^{126}$ Possible explanations for vitamin $\mathrm{D}$ deficiency in HIV populations is the over-activation of TNF- $\alpha$ due to HIV itself and AIDS-associated infections, which block the stimulatory effect of parathyroid hormone on renal 1, $\alpha$-hydroxylase. ${ }^{126}$ Another potential explanation is HIV nephropathy which leads to a defect in the $1, \alpha$ hydroxylation of $25(\mathrm{OH}) \mathrm{D}$ into $1,25(\mathrm{OH})_{2} \mathrm{D}$ which should normally occur in the kidney in response to low $1,25(\mathrm{OH})_{2}$ D. ${ }^{126,127}$ Careful monitoring of vitamin D should be undertaken in any HIV patients with abnormal kidney function. ${ }^{126,127}$ Low alimentary intake due to poor appetite, liver impairment and the interference of antiretroviral drugs with vitamin D metabolism are other likely explanations. $^{126}$ Reciprocally, vitamin D deficiency in this population could be responsible for the severity and pathogenicity of infections in patients with HIV. ${ }^{128}$ The majority of HIV-infected people live in areas of the world where nutritional deficiencies are highly prevalent. It is widely distributed in Africa where there is documented vitamin D deficiency, as it is well known that people of black ethnicities are more prone to vitamin D deficiency than people of white ethnicities. ${ }^{126}$ There might be a hope of better outcomes by emphasizing adequate vitamin D stores in all HIV-infected patients who are starting cART.

Several researchers have studied the correlation between HIV and vitamin D deficiency. ${ }^{126}$ The role of vitamin $\mathrm{D}$ in mediating $\mathrm{HIV}$ infection is proposed to be related to its immunomodulatory properties via VDRs expressed on adaptive and innate immune cells. In addition, vitamin D is closely implicated in the functioning of $\mathrm{T}$ and $\mathrm{B}$ lymphocytes in the adaptive immune system by regulating the activation of lymphocytes directly and by affecting the antigen-presenting cells (APC). ${ }^{129}$ The effects of vitamin D on HIV infection in vitro have been examined in terms of its possible role on monocyte/ macrophage function and on HIV expression and replication in monocytes/macrophages. One study of monocytes from 10 AIDS patients showed that incubation with $1,25(\mathrm{OH})_{2} \mathrm{D}$ resulted in a significant increase in chemotaxis. In another experiment, $1,25(\mathrm{OH})_{2} \mathrm{D}$ tended to decrease the number of Mycobacterium avium bacteria in macrophages from HIV-positive patients which might decrease morbidity in these population. ${ }^{130}$

Vitamin D also induces antiviral gene expression, reduces the viral co-receptor $\mathrm{C}-\mathrm{C}$ chemokine receptor type 5 (CCR5) on $\mathrm{CD}^{+}$T-cells, and promotes an HIV1-restrictive CD38+HLA-DR+ immunophenotype in vitro study, leading to HIV-1 infection inhibition in T cells. ${ }^{131}$ These findings should raise the hope for consideration of vitamin D supplementation in HIV-infected patients.

Some studies evaluated the epidemiological relevance and others evaluated the clinical outcomes of vitamin D deficiency in HIV patients. Deficiencies of several micronutrients are associated with higher rate of progression to AIDS and HIV-related morbidity and mortality. ${ }^{126}$ EuroSIDA, a prospective observational open cohort study of 16,599 HIV-1-infected persons, found that having a 25 $(\mathrm{OH}) \mathrm{D}$ level in the lowest titer $(<12 \mathrm{ng} / \mathrm{mL})$ was robustly associated with the occurrence of AIDS events and allcause mortality with a median follow-up of 5 years. ${ }^{132}$ While those with higher levels (i.e. $>20 \mathrm{ng} / \mathrm{mL}$ ) have significantly lower risk of clinical progression during the subsequent follow-up. ${ }^{132}$

Since $\mathrm{CD}^{+}$count recovery has a crucial role in decreasing mortality in HIV patients, longitudinal studies analyzed the effects of vitamin $\mathrm{D}$ status on $\mathrm{CD}^{+}{ }^{+} \mathrm{T}$-cell recovery among HIV-positive patients. Aziz et al. examined $204 \mathrm{HIV}$-infected women and concluded that vitamin $\mathrm{D}$ deficiency was associated with diminished late $\mathrm{CD} 4^{+}$ recovery after highly active antiretroviral therapy (HAART) initiation. ${ }^{133}$ Haug et al. studied the association between low vitamin D levels and morbidity in HIVinfected subjects. ${ }^{134}$ In their study, vitamin D serum level $\left[1,25(\mathrm{OH})_{2} \mathrm{D}\right]$ was significantly positively correlated with $\mathrm{CD}^{+}$counts of HIV-infected people $(\mathrm{P}<0.05){ }^{134}$ Moreover, abnormally low vitamin D in those patients was significantly associated with shorter survival than in other patients with HIV $(\mathrm{P}<0.01) .^{134}$ In another study, $\mathrm{CD}^{+}$counts in patients with AIDS and non-AIDS diseases (liver, cardiovascular, renal, and cancer) were studied over a median follow-up of 5 years. ${ }^{135}$ This study concluded that higher $\mathrm{CD}^{+}$counts were associated with lower rates of AIDS and non-AIDS related diseases in 
HIV subjects on HAART. ${ }^{135}$ Several other prospective studies concluded that vitamin D deficiency was associated with late $\mathrm{CD} 4^{+}$recovery after HAART initiation possibly because vitamin $\mathrm{D}$ is a crucial element for the activation of immune defenses. ${ }^{133}$ A second explanation could be related to the role of vitamin $\mathrm{D}$ in stimulating the production of naive $\mathrm{T}$ cells. ${ }^{133} \mathrm{~A}$ third explanation is that vitamin $\mathrm{D}$ plays a role in down-regulating the transcription of HIV RNA from latently infected $\mathrm{CD}^{+}$cells by the reduction in the capacity of TNF- $\alpha$ of transcripting HIV RNA. ${ }^{136}$ These mechanisms might explain the conclusion of several studies that support the connection between vitamin $\mathrm{D}$ deficiency and the incidence and severity of infectious diseases in HIV patients, including advanced AIDS, MTB, and HCV. ${ }^{136}$ Vitamin D has a potential role in preventing HIV-related mortality, based on its extensive actions in immune and metabolic function. ${ }^{136}$ Based on existing data, it might have a crucial role in morbidity and HIV-related opportunistic infections in HIV patients with low vitamin D level. However, this association has not been examined in large studies.

Vitamin D levels were assessed in a prospective cohort study of $884 \mathrm{HIV}$-infected pregnant women at enrollment in Tanzania. ${ }^{128}$ HIV-related complications were monitored during a median of 70 months follow-up. Women with low vitamin D levels had significantly higher incidence of acute upper respiratory infections (HR: 1.27 [1.04-1.54]) diagnosed during the first 2 years of follow-up. In addition, low vitamin D status was a major risk factor for wasting and HIV-related complications such as thrush. ${ }^{128}$ In a cohort trial of HIV-infected adults from predominantly low- and middle-income countries, deficiencies in Vitamin D upon HAART initiation were independently associated with increased risk of incidence of TB in the ensuing 96 weeks. ${ }^{137}$ Coelho et al., in their study, concluded that $1 \mathrm{ng} / \mathrm{mL}$ of calcidiol $(25(\mathrm{OH}) \mathrm{D})$ was demonstrated to increase $\mathrm{CD} 4^{+}$cell count by 3.3 cells $/ \mathrm{mm}^{3}$, suggesting a useful role of vitamin D supplementation on immune recovery. ${ }^{138}$ Dougherty et al. reported similar conclusions, i.e. they noted a significant increase in $\mathrm{CD}^{+}$count after vitamin D supplementation. ${ }^{139}$ Clearly, Vitamin D has great potential hopes for HIV patients: its deficiency was associated with rapid progression to AIDS, to mortality and to $\mathrm{CD} 4^{+}$counts. Currently, the available evidence suggests that there is a potential role for vitamin D repletion in patients living with HIV. However, comprehensive studies are required to define an adequate supplementation protocol for these individuals. Confirmation of this association would be crucial because vitamin D supplementation could represent an inexpensive and simple method to improve health and quality of life in HIV-infected patients, in particular in resource-limited settings. Despite the absence of substantial evidence the Endocrine Society Clinical Practice Guidelines have recommended that $25(\mathrm{OH}) \mathrm{D}$ measurements are reasonable in HIV groups of people who are on HAART as they are at a higher risk for vitamin D deficiency. ${ }^{24}$ The prompt response to optimize vitamin D status is expected. The question that remains to be answered now is should empiric replacement therapy with vitamin D be considered in any patient starting HAART.

\section{Vitamin D and COVID-I9}

Currently, the world is facing the COVID-19 pandemic that is caused by SARS-CoV-2, as declared by the World Health Organization (WHO) in March 2020. ${ }^{140,141}$ This infection by a new coronavirus strain that emerged in Wuhan, Hubei, China, in late 2019, and the disease was named COVID-19 by the WHO on February 11, 2020. However, the coronavirus family had previously caused two epidemics. The first epidemic started in China in 2002, named severe acute respiratory syndrome, (SARS)$\mathrm{CoV}$, and the next epidemic was reported in the Middle East, named Middle East respiratory syndrome, (MERS)CoV.

These infections by coronaviruses began with animalto-human infection. Similar to SARS-CoV and MERS$\mathrm{CoV}$ infections, ${ }^{142}$ patients infected with SARS-CoV-2 have clinical manifestations including fever, nonproductive cough, dyspnea, myalgia, normal or decreased leukocyte counts, and radiological changes of pneumonia. ${ }^{143}$ The leading cause of death in patients infected with SARS-CoV-2 is severe acute respiratory distress syndrome (ARDS), which is also a common immunopathological event of SARS-CoV and MERS$\mathrm{CoV} .{ }^{144}$ ARDS is a consequence of an exaggerated inflammatory response accompanied by uncontrolled oxidative stress as well as an inflammatory reaction in the lungs. ${ }^{91}$ The COVID-19 pandemic has spread rapidly, causing significant morbidity and mortality worldwide. It has been reported that patients over 60 years showed some systemic alterations, which include disturbance in normal plasma levels of lymphocytes, thrombocytes, C-reactive protein, and lactate dehydrogenase enzyme. ${ }^{145}$ An increase in thrombi/emboli formation was also described in COVID19 cases and it had been claimed as the cause of oxygen 
desaturation and acute respiratory distress in those patients. ${ }^{146,147}$ Therefore, it is essential to understand the underlying chemical and immunopathologic process in order to find the appropriate approach to the management and prevention of SARS-CoV-2 infection. The following sections will explain part of the causal pathological process that may occur in patients with COVID-19 and how vitamin D levels and its other related factors can contribute to overcoming this infection and alleviate its pathological consequence on the human body systems.

\section{Viral Entrance and Cytokine Storm}

When the virus is inhaled, it enters the epithelial cells of the nasal cavity, where replication starts within 1-2 days, but the patient remains asymptomatic and without any significant effects caused by innate immune cells. ${ }^{148}$ As the virus moves down to the lower respiratory tract and reaches the lungs, this triggers a strong innate immune response. Similar to SARS-CoV, SARS-CoV-2 needsACE2 as a receptor that binds to its spike (S) protein to enter the target cells. When this endocytosis occurs, it enhances the release of ACE2 from the membrane, and together with further down-regulation of the ACE2 expression by SARS-CoV-2, results in a loss of counter regulatory activity to $\operatorname{RAS}^{21,149}$ (Figure 3 ). This imbalance in RAS regulation increases the accumulation of Angiotensin II and renin synthesis resulting in extensive release of proinflammatory cytokines (IFN- $\alpha$, INF- $\gamma$, TNF- $\alpha$, IL-1 13 , IL-6, etc.) and chemokines (CCL2, CCL3, CCL5, CXCL8, etc.) into circulation by immune effector cells in SARS-CoV infection, and thus initiating a cytokine storm. ${ }^{150,151}$ Consequently, as observed in COVID-19 patients, this cytokine storm leads to a violent attack to the body with a series of vascular changes that may contribute both to ARDS and to cardiac and vessels injury especially in any preexisting lesion of the heart. ${ }^{152}$ Vitamin D can also effectively inhibit NFאB activation and thus decreases the inflammatory response to viral infections in airway epithelium without jeopardizing viral clearance ${ }^{79}$ (Figure 3). Therefore, the effects of SARS-CoV-2 on RAS will be worse if the patient is suffering from a vitamin $\mathrm{D}$ deficiency status. This is supported by the findings of studies that revealed vitamin D is a negative regulator of renin expression and RAS activity and thus can counteract the imbalance resulting from SARS-CoV-2 infection and the cytokine storm. $^{77}$

\section{The Pathogenesis of SARS-COV-2}

Once SARS-CoV-2 enters the cells, the immune system can recognize the whole virus or part of its surface epitopes, thus provoking the innate or adaptive immunity. Perception of the virus occurs via pathogen recognition receptors (PRRs), namely Toll-like receptors (TLRs) that stimulate the release of interferon (INF). ${ }^{153}$ In addition, as the virus enters the cells, it is presented to the APC, which will trigger the antiviral immunity in the infected cells by producing various cytokines, antibodies, and killing cells. Similar to SARS-CoV, the antigenic peptides of SARSCoV-2 are presented by major histocompatibility complex (MHC) (or human leukocyte antigen (HLA) in humans) and then recognized by virus-specific cytotoxic $\mathrm{T}$ lymphocytes (CTLs) that play a vital role in clearance and killing of viral infected cells. ${ }^{153}$ Dendritic cells act as APC and are involved in the presentation of viral antigenic peptides complexed with MHC I and II molecules, which in turn promotes the cytokine release and the cytotoxic activity of CD8. ${ }^{154}$ Therefore, the overall result of the immune response to the virus is enhancing the secretion of pro-inflammatory cytokines such as TNF- $\alpha$, IL-6, and IFN- $\alpha /-\gamma$, together with reducing anti-inflammatory cytokines. $^{154}$

As previously stated, vitamin D may contribute effectively to reduce the production of proinflammatory T helper (Th) 1 cytokines (TNF- $\alpha$ and IFN- $\gamma$ ) and increases the expression of anti-inflammatory cytokines by macrophages, ${ }^{57,155}$ leading to further control of cytokine storm effects. Accordingly, vitamin D has overall modulation effects on the adaptive immune response that produces immune tolerance in the body. ${ }^{57}$ On the other hand, innate cellular immunity can be reinforced by the action of vitamin D in macrophage, relatively through the activation of TLR2/1 to increase the expression of AMP cathelicidin (LL-37) and defensins ${ }^{156,157}$ (Figure 2A). This means that VDR signaling is linked to the activation of AMP cathelicidin to modulate the autophagy system, cytokine/chemokine generation, and crosstalk with innate and adaptive immune responses during infection. ${ }^{156,157}$

\section{Evasion of Immune System}

In order to survive within the host cells, coronavirus adopts multiple strategies to avoid immune sensing. Similar mechanisms of evasion can be postulated and adopted to SARS-CoV -2 which has little reported information as of yet. Any microbial agent possesses pathogen-associated molecular patterns (PAMPs) that can be recognized by pattern recognition receptors (PRRs) within the host cells to control its invasion. Accordingly, SARS-CoV and MERS-CoV enhance the production of double membrane vesicles within which they can 
replicate, thereby avoiding the host detection of their dsRNA. ${ }^{157}$ In addition, similar to SARS-CoV-1, SARS-CoV -2 can inhibit the production of INF classes in the infected bronchial cells lines culture. ${ }^{158}$ This cellular culture's result is consistent with the finding of a clinical study that revealed that patients with severe COVID-19 had demonstrated a marked decrease in IFN-I compared with patients with mild or moderate disease. ${ }^{159}$ These findings have supported the proposal that vitamin D3 may be of great benefit to combat SARS-CoV -2 infection. $^{159}$

\section{Consequences in Patients with Vitamin D Deficiency and Concurrent Risk Factors During SARS-CoV-2 Infection}

Febrile illness, as a result of a systemic influx of pyrogenic cytokines, is considered as the main symptom of COVID-19 in $85 \%$ of cases, whereas in $45 \%$ of cases, the early onset of symptoms that were reported included fever, sore throat, nasal congestion, dyspnea, dry cough, and radiological changes. ${ }^{160}$ As mentioned previously, lung tissue damage induced by SARS-CoV-2 may result in ARDS which is usually accompanied with septic shock, both of which are considered the leading cause for intensive care unit (ICU) admissions and for increased mortality rates; particularly in patients over 60 years of age. ${ }^{160}$ It was also determined that patients who smoke in older age groups showed a higher density of ACE2 receptors that increased their susceptibility to a poorer outcome from COVID-19. ${ }^{161}$

In addition, most COVID-19 patients admitted to hospital have presented signs of severe inflammation and low nutritional status including vitamin $\mathrm{D}$ deficiency. Moreover, within a few days, a significant percentage of them develop respiratory failure requiring non-invasive ventilation or continuous positive airway pressure. ${ }^{160}$ The damaged respiratory endothelium during the entrance of SARS-CoV-2 through ACE2 receptors leads to endothelial dysfunction that in turn interferes with the binding of inadequately present vitamin $\mathrm{D}$ to its receptor (VDR), resulting in further progression of the inflammatory process and increased risk of severity in COVID-19. ${ }^{162}$ Lately, several researchers have confirmed the positive effects of GSH, that acts as a potent antioxidant, along with its precursor, L-cysteine, on vitamin D metabolism. ${ }^{41}$ Thus individuals with depleted GSH become less able to overcome the oxidative stress that develops during infections. They will also be unable to enhance the action of vitamin D.
Furthermore, obesity may diminish the immune function as a result of increased adiposity which may damage the alveoli, wherein viral pathogenesis and damaged immune cells could contribute to a maladaptive cycle of immunological processes. This condition may become worse if the patient has existing related chronic disease, particularly high blood pressure and diabetes mellitus. ${ }^{163}$ In patients with type 2 diabetes mellitus, hyperinsulinemia promotes a further decrease in vitamin D via trapping within adipocytes, and thus decreasing the plasma membrane's negative charge between red blood cells, platelets, and endothelial cells, resulting in increased agglutination and thrombosis. ${ }^{164}$

\section{Experimental and Clinical Studies Showing Variable Effects of Vitamin D on SARS-COV-2}

Clinical studies showed that the most vulnerable populations for COVID-19 are the elderly population and those with vitamin D deficiency. ${ }^{3}$ Older patients with comorbidities and below-normal vitamin D have a higher rate of mortality. ${ }^{165}$ Vitamin D deficiency was also reported to be associated with an increased risk of severity in COVID-19. ${ }^{166}$ It seems highly probable that appropriate supplementation of vitamin D for populations with a high prevalence of vitamin D deficiency may decrease the risk of severe COVID-19 consequences. ${ }^{166}$

In animal models of acute respiratory distress syndrome (ARDS), vitamin D pretreatment was beneficial in reducing lung injury by re-modulation of RAS expression and ACE2 activity which is an important receptor for COVID-19 pathogenesis. ${ }^{167}$ Experts hypothesize that vitamin D supplementation may enhance immunity and help humans to fight COVID-19 and its aggressive effects on all organ systems. ${ }^{168} \mathrm{~A}$ recent retrospective study of laboratory confirmed SARS-CoV-2 infection suggested that vitamin D supplementation could possibly improve clinical outcomes of patients infected with COVID-19 based on increasing odds ratio of having a mild outcome when serum 25(OH)D level increases. ${ }^{169}$

Yet there are insufficient cohort studies and clinical trials to define the role of vitamin $\mathrm{D}$ in the prevention of COVID-19 infections and/or infection severity. An initial data reported by Alipio ${ }^{169}$, found that the severity of the infection is highly correlated to the vitamin D3 levels. ${ }^{169}$ In that study, the author revealed that patients with an adequate status of vitamin D3 $(>30 \mathrm{ng} / \mathrm{mL})$ manifested moderate COVID-19 symptoms, while $72.8 \%$ of patients 
with vitamin D3 deficiency $(<20 \mathrm{ng} / \mathrm{mL})$ had severe symptoms. ${ }^{169}$ Achieving the appropriate levels of serum $25(\mathrm{OH}) \mathrm{D}$ is crucial for VDR signaling to mediate the defense process against viral respiratory infections ${ }^{169}$ by modulating the TLR expression.

Although there are extensive experimental and clinical studies on the role of vitamin D in the immunomodulation of the adaptive immune system, controversial clinical results still exist. There are many randomized controlled trials that were done in the field of vitamin $\mathrm{D}$ and its effect on infections, however, most of these trials have multiple limitations that could be attributed to lack of homogeneity as vitamin $\mathrm{D}$ absorption varies depending on ethnicity, season variations, geographic distribution, vitamin D dosage variations used in in vivo and in vitro studies, as well as on the specific laboratory method that was used for measurement. In addition, vitamin D controls the expression of several genes relevant to cellular proliferation, differentiation, apoptosis, and angiogenesis, however, genetic variation in the vitamin $\mathrm{D}$ pathway influences the upper respiratory tract infection risk, ${ }^{169}$ and so this may explain the variable results obtained in response to vitamin D supplementation.

Several observational epidemiological studies and randomized controlled trials have addressed the role of high doses of vitamin D in respiratory infections. ${ }^{169}$ A recent review suggested using vitamin $\mathrm{D}$ loading doses of 200,000-300,000 IU in 50,000 IU capsules would help reduce the risk and severity of COVID-19. ${ }^{2}$ On the contrary, a recent randomized, double-blind, placebocontrolled clinical trial revealed that a single high dose of vitamin D3 did not significantly decrease length of stay in hospital or improve any other clinically relevant outcomes among hospitalized patients having moderate to severe COVID-19 infections. However, several limitations were encountered in this study among which are the low percentage of patients enrolled and the presence of several comorbidities in the patients who were subjected to a wide range of medication regimens that could have affected the results due to heterogeneity. ${ }^{170}$

To date, several drugs have been tried for treating COVID-19 but no evidence-based clinical trials have been published yet that provide data about their safety and efficacy. ${ }^{171-175}$ These include the antivirals interferon $\alpha \quad$ (IFN- $\alpha$ ), Remdesivir, and Favipiravir. ${ }^{176}$ Hydroxychloroquine was commonly used for the reduction of viral load but it was found to increase mortality in certain groups. ${ }^{172}$ Vitamin D is a proposed safer and more adequate alternative for other ineffective drugs. ${ }^{177,178}$ Since vitamin D measurement and supplementation is available in all hospitals worldwide, and since it is a simple and harmless supplement with a potentially significant role in reducing COVID-19 severity, it is reasonable to widely evaluate vitamin D supplementation in COVID-19 patients as a possible treating method or as adjunctive therapy. Alternatively, we might hypothesize that mass treatment of vitamin $\mathrm{D}$ deficiency might be a preventable tool against viral infections including COVID-19 particularly during winter months.

In addition, based on the recent studies that confirm the positive correlation between the circulatory level of 25 $(\mathrm{OH}) \mathrm{D}$ and the redox status as well as the ability of GSH to increase serum 25(OH)D. The combination of L-cysteine and vitamin D supplements might be of great help in overcoming the pathogenic process of COVID 19. ${ }^{38,39,41}$ Moreover, GSH that is enhanced by adequate levels of vitamin $\mathrm{D}$, has a role in preventing the oxidant stress developed during the inflammatory process of infection. ${ }^{42}$ Therefore, combined supplementation of vitamin D with L-cysteine, a precursor of GSH, is a step that would prevent and/or decrease the morbidity and mortality of COVID-19 infections.

Lastly, a recent study (still in a preprint) by Roth et al. reported the ability of LL-37 to bind to the SARS-CoV-2 $\mathrm{S}$ protein and inhibit its binding to the ACE2 receptor, and thus possibly prevent viral entry into the cells. These findings confirmed the biochemical association between vitamin D, LL-37, and the severity of COVID 19 infections. ${ }^{179}$ Therefore, this study can support the prophylactic use of vitamin D to protect against SARS-CoV-2 infections via inducing LL-37, or via direct use of LL-37 by inhalation and systemic application to diminish the severity of COVID-19 infections. ${ }^{179}$

Taken together, vitamin D supplementation can be considered as a safe and supportable therapy for these diseases; however, it necessitates the conduct of largerscale studies over longer durations of therapy to confirm this assumption.

\section{Conclusion}

Vitamin D has a role in the modulation of the inflammatory immune response via controlling gene expression of VDRs. It reduces pro-inflammatory cytokines as TNF- $\alpha$ and IFN- $\gamma$, and increases anti-inflammatory cytokines such as IL-10. Vitamin D also reduces thrombo-embolic events 
associated with infections. It exerts its anticoagulant effect by up-regulating the expression of anticoagulant glycoproteins (especially defensin), down-regulating the expression of critical coagulation factors, inhibition of RAS system, and induction of ACE2 receptors. In addition, vitamin D has a significant role in decreasing the oxidative stress that occurs during infections via up-regulating the expression of GSH.

Vitamin D deficiency is reported to increase the risk of several infections such as tuberculosis, influenza, HIV, and COVID-19. Vitamin D supplement in these cases is proposed to reduce the risk of developing the infection, alleviate the severity, or prevent serious complications. However, no solid evidence-based data exists to date to confirm or negate this hypothesis. Results from different studies in current literature are conflicting. In influenza, vitamin $\mathrm{D}$ has been found to have a preventive effect against influenza virus infection via enhancing the innate immunity by up-regulation and production of antimicrobials such as defensin in primary human monocytes, neutrophils, natural killer cells and in the peripheral cells that line the respiratory tract. In tuberculosis, vitamin D supplementation inhibited the growth and replication of MTB through the production of AMP cathelicidin and subsequent killing of intracellular MTB. In HIV patients, vitamin $\mathrm{D}$ deficiency is prevalent. This deficiency is due to impairment of $1, \alpha$-hydroxylase in patients with HIV due to over-activation of TNF- $\alpha$ and HIV-nephropathy. Reciprocally, vitamin $\mathrm{D}$ deficiency in HIV patients delays $\mathrm{CD} 4^{+}$recovery. Vitamin D has a further essential role in the prevention of COVID-19 infection. Coronavirus enters the host cell via binding to ACE2 receptors, then inhibits the expression of these receptors, resulting in lung injury and pneumonia. On the other hand, vitamin D enhances the expression of ACE2 receptors via its negative impact on RAS, and subsequently reduces the cytokine storm and thus the severity of the COVID-19 infection. Vitamin D also reduces the cytokine storm associated with SARS-CoV-2 infection via modulating adaptive immunity, suppression of Th1 responses, and suppression of cytokine synthesis and release.

Vitamin D deficiency is a common and widespread condition in all parts of the world, taking into respect different ethnicities, geographic distributions, genetic variations in vitamin D pathways and other comorbid risk factors encountered namely obesity, diabetes, and hypertension. This may explain that although there were a considerable number of studies that showed the beneficial effects of vitamin D supplementation in various infections including SARS-CoV-2, controversial results were reported by others. Since vitamin D measurement is available in all hospitals worldwide and vitamin D supplementation is a simple and harmless method with a likely promising role in several infections' prevention and/or treatment (including COVID-19), it is reasonable to conduct large, well-designed, multi-centered, randomized controlled clinical trials to address the role of vitamin D supplementation in these conditions. This may lead to the following valid questions: whether maintaining adequate vitamin $\mathrm{D}$ stores in the body can prevent infections or not, as well as, whether adjuvant therapy with L-cysteine can improve the outcome of vitamin D supplementation via enhancing its metabolism or not.

It is clear that vitamin D is linked with many infections and infectious processes, although further studies are needed. We recommend screening vulnerable populations and optimizing their care accordingly. If, however, widespread screening is difficult or inaccessible, empirical treatment with replacement doses of vitamin $\mathrm{D}$ can be given to at-risk populations, such as people who have poor exposure to the sun i.e., inmates, nursing home populations and patients suffering from chronic infections. Optimization of vitamin D stores during winter months will decrease the risk of acute viral infections. The replacement dose that we suggest is 50,000 units of cholecalciferol per week for a period of three months to be given with adequate calcium intake for concurrent bone health benefits.

\section{Abbreviations}

1,25(OH)2D, 1,25-dihydroxyvitamin $\mathrm{D} ; 25(\mathrm{OH}) \mathrm{D}, \quad 25-$ hydroxyvitamin D; ACE, Angiotensin-converting enzyme; ARDS, Acute respiratory distress syndrome; AIDS, Acquired immunodeficiency syndrome; AMP, Antimicrobial peptide; APC, Antigen-presenting cell; ARTI, Acute respiratory tract infections; CAMP, Cyclic adenosine monophosphate; cART, Combined antiretroviral therapy; CCR-5, $\mathrm{C}-\mathrm{C}$ chemokine cytokine type 5; CD4, cluster of differentiation 4; CRP, C-reactive protein; CTLs, cytotoxic T lymphocytes CVD, Cardiovascular disease; DVT, Deep vein thrombosis; FGF23, Fibroblast-like growth factor-23; GCSF, granulocyte colony-stimulating factor; HAART, Highly active antiretroviral therapy; hCAP-18, human cathelicidin antimicrobial peptide; $\mathrm{HCV}$, hepatitis $\mathrm{C}$ virus; $\mathrm{HIV}$, human immunodeficiency virus; HLA, Human leukocyte antigen; IFN- $\alpha$, Interferon alpha; IFN- $\gamma$, Interferon gamma; IL2R, interleukin 2R; IL-6, interleukin 6; IL, Interleukin; MCP1, Macrophage chemotactic protein-1; MERS-CoV, Middle East Respiratory Syndrome Coronavirus; MHC, Major histocompatibility complex; MIP, Macrophage inflammatory protein; 
MTB, Mycobacterium tuberculosis; NR, nuclear receptors; PAMPs, Pathogen-associated molecular patterns; PE, Pulmonary embolism; PRRs, Pattern recognition receptors (PRRs) PTH, Parathyroid hormone; RAS, Renin-angiotensin system; RNA, Ribonucleic acid; SARS, Severe acute respiratory syndrome; TB, tuberculosis; Th1, T helper cell type 1; TNF- $\alpha$, Tumor necrosis factor alpha; TLR, Toll-like receptor; VTE, Venous thromboembolism; UV, Ultraviolet.

\section{Acknowledgment}

The authors gratefully acknowledge Alzaidi chair of research in rheumatic diseases, for their sponsorship and support. We would also like to thank Dr. Rola Hassan for composing the figures.

\section{Disclosure}

Prof. Dr. Hani Almoallim reports non-financial support and publication fees from Alzaidi Chair of Research in Rheumatic Diseases, Umm Al Qura University, during the conduct of the study. The authors reported no other potential conflicts of interest for this work.

\section{References}

1. Aranow C. Vitamin D and the immune system. J Invest Med. 2011;59(6):881-886. doi:10.2310/JIM.0b013e31821b8755

2. Grant WB, Lahore H, McDonnell SL, et al. Evidence that vitamin d supplementation could reduce risk of influenza and covid-19 infections and deaths. Nutrients. 2020. doi:10.3390/nu12040988

3. Ilie PC, Stefanescu S, Smith L. The role of vitamin D in the prevention of coronavirus disease 2019 infection and mortality. Aging Clin Exp Res. 2020;32(7):1195-1198. doi:10.1007/s40520020-01570-8

4. Ali N. Role of vitamin D in preventing of COVID-19 infection, progression and severity. J Infect Public Health. 2020;13 (10):1373-1380. doi:10.1016/j.jiph.2020.06.021

5. Palacios C. Is vitamin D deficiency a major global public health problem? J Steroid Biochem Mol Biol. 2014.

6. Edwards MH. The Global Epidemiology Of Vitamin D Status Jarcp The Journal Of Aging Research And Clinical Practice. $J$ Aging Res Clin Pract. 2014.

7. Lips P, Cashman KD, Lamberg-Allardt C, et al. Current Vitamin D status in European and Middle East countries and strategies to prevent Vitamin D deficiency: a position statement of the European Calcified Tissue Society. Eur J Endocrinol. 2019. doi:10.1530/EJE-18-0736

8. Carmeliet G, Dermauw V, Bouillon R. Vitamin D signaling in calcium and bone homeostasis: a delicate balance. Best Pract Res Clin Endocrinol Metab. 2015;29(4):621-631. doi:10.1016/j. beem.2015.06.001

9. Lerner V, Miodownik C. Vitamin D Deficiency. J Infect Public Health. 2012. doi:10.5005/jp/books/11937_24

10. Souberbielle JC, Body JJ, Lappe JM, et al. Vitamin D and musculoskeletal health, cardiovascular disease, autoimmunity and cancer: recommendations for clinical practice. Autoimmun Rev 2010;9(11):709-715. doi:10.1016/j.autrev.2010.06.009
11. Christakos S, Ajibade DV, Dhawan P, Fechner AJ, Mady LJ. Vitamin D: metabolism. Endocrinol Metab Clin North Am. 2010;39(2):243-253. doi:10.1016/j.ecl.2010.02.002

12. Christakos S, Dhawan P, Verstuyf A, Verlinden L, Carmeliet G. Vitamin D: metabolism, molecular mechanism of action, and pleiotropic effects. Physiol Rev. 2015. doi:10.1152/ physrev.00014.2015

13. Á G, Plaza-Diaz J, Mesa MD. Vitamin D: classic and Novel Actions. Ann Nutr Metab. 2018;72(2):87-95. doi:10.1159/ 000486536

14. Schramm S, Lahner H, Jöckel KH, Erbel R, Führer D, Moebus S. Impact of season and different vitamin $\mathrm{D}$ thresholds on prevalence of vitamin D deficiency in epidemiological cohorts - a note of caution. Endocrine. 2017;56(3):658-666. doi:10.1007/s12020017-1292-7

15. Marino R, Misra M. Extra-skeletal effects of vitamin D. Nutrients. 2019;11(7):1460. doi:10.3390/nu11071460

16. Li Y, Ding S. Serum 25-Hydroxyvitamin D and the risk of mortality in adult patients with Sepsis: a meta-analysis. $B M C$ Infect Dis. 2020;20(1):1-10.

17. Gombart AF. The vitamin D-antimicrobial peptide pathway and its role in protection against infection. Future Microbiol. 2009;4 (9):1151-1165. doi:10.2217/fmb.09.87

18. Baeke F, Takiishi T, Korf H, Gysemans C, Mathieu C. Vitamin D: modulator of the immune system. Curr Opin Pharmacol. 2010;10 (4):482-496. doi:10.1016/j.coph.2010.04.001

19. Zhu J, Deluca HF. Vitamin D 25-hydroxylase - Four decades of searching, are we there yet? Arch Biochem Biophys. 2012;523 (1):30-36. doi:10.1016/j.abb.2012.01.013

20. Zhu JG, Ochalek JT, Kaufmann M, Jones G, DeLuca HF. CYP2R1 is a major, but not exclusive, contributor to 25-hydroxyvitamin D production in vivo. Proc Natl Acad Sci U S A. 2013;110 (39):15650-15655. doi:10.1073/pnas.1315006110

21. Paz Ocaranza M, Riquelme JA, García L, et al. Counterregulatory renin-angiotensin system in cardiovascular disease. Nat Rev Cardiol. 2020;17(2):116-129. doi:10.1038/s41569-0190244-8

22. Haussler MR, McCain TA. Basic and Clinical Concepts Related to Vitamin D Metabolism and Action. N Engl J Med. 1977. doi:10.1056/nejm197711032971804

23. Henry HL. Regulation of vitamin D metabolism. Best Pract Res Clin Endocrinol Metab. 2011;25(4):531-541. doi:10.1016/j. beem.2011.05.003

24. Holick MF, Binkley NC, Bischoff-Ferrari HA, et al. Evaluation, treatment, and prevention of vitamin D deficiency: an endocrine society clinical practice guideline. J Clin Endocrinol Metab. 2011;96(7):1911-1930. doi:10.1210/jc.2011-0385

25. Jones G, Strugnell SA, DeLuca HF. Current understanding of the molecular actions of vitamin $\quad$ D. Physiol Rev. 1998;78 (4):1193-1231. doi:10.1152/physrev.1998.78.4.1193

26. Seamans KM, Cashman KD. Existing and potentially novel functional markers of vitamin D status: a systematic review. Am J Clin Nutrition. 2009;89(6):1997S-2008S. doi:10.3945/ajcn.2009.27230D

27. Plum LA, DeLuca HF. The functional metabolism and molecular biology of vitamin D action. In: Vitamin D. Springer; 2010:61-97.

28. Haussler MR, Haussler CA, Jurutka PW, et al. The vitamin D hormone and its nuclear receptor: molecular actions and disease states. J Endocrinol. 1997. doi:10.1677/joe.0.154S057

29. Feldman D, Krishnan AV, Swami S. Vitamin D. Biology, Actions, and Clinical Implications. Osteoporosis. 2013. doi:10.1016/B9780-12-415853-5.00013-3

30. Wang Y, Zhu J, DeLuca HF. Where is the vitamin D receptor? Arch Biochem Biophys. 2012. doi:10.1016/j.abb.2012.04.001

31. Daniel A. 1-s2.0-S0891584901004804-main.pdf. Free Radic Biol Med. 2001;30(11):1191-1212. doi:10.1016/s0891-5849(01) 00480-4 
32. Hammond CL, Lee TK, Ballatori N. Novel roles for glutathione in gene expression, cell death, and membrane transport of organic solutes. J Hepatol. 2001;34(6):946-954. doi:10.1016/S01688278(01)00037-X

33. Ratnayake S, Dias IHK, Lattman E, Griffiths HR. Stabilising cysteinyl thiol oxidation and nitrosation for proteomic analysis. J Proteomics. 2013;92:160-170. doi:10.1016/j.jprot.2013.06.019

34. Curtis JM, Hahn WS, Long EK, Burrill JS, Arriaga EA, Bernlohr DA. Protein carbonylation and metabolic control systems. Trends Endocrinol Metab. 2012;23(8):399-406. doi:10.1016/j.tem.2012.05.008

35. Dalle-Donne I, Rossi R, Giustarini D, Milzani A, Colombo R. Protein carbonyl groups as biomarkers of oxidative stress. Clin Chim Acta. 2003;329(1-2):23-38. doi:10.1016/S0009-8981(03)00003-2

36. Barreiro E, Hussain SNA. Protein carbonylation in skeletal muscles: impact on function. Antioxidants Redox Signal. 2010;12 (3):417-429. doi:10.1089/ars.2009.2808

37. Ballatori N, Krance SM, Notenboom S, Shi S, Tieu K, Hammond CL. Glutathione dysregulation and the etiology and progression of human diseases. Biol Chem. 2009;390(3):191-214. doi:10.1515/BC.2009.033

38. Grant WB, Al Anouti F, Moukayed M. Targeted 25-hydroxyvitamin D concentration measurements and vitamin D3 supplementation can have important patient and public health benefits. Eur J Clin Nutr. 2020;74(3):366-376. doi:10.1038/ s41430-020-0564-0

39. Posner J, Bradley S, Peterson JAR. NIH jessica. Bone. 2008;23 (1):1-7. doi:10.1111/cen.12449.Vitamin

40. Farhangi MA, Najafi M. Dietary total antioxidant capacity (TAC) among candidates for coronary artery bypass grafting (CABG) surgery: emphasis to possible beneficial role of TAC on serum vitamin D. PLoS One. 2018;13(12):1-13. doi:10.1371/journal. pone. 0208806

41. Jain SK, Kanikarla-Marie P, Warden C, Micinski D. L-cysteine supplementation upregulates glutathione (GSH) and vitamin D binding protein (VDBP) in hepatocytes cultured in high glucose and in vivo in liver, and increases blood levels of GSH, VDBP, and 25-hydroxy-vitamin D in Zucker diabetic fatty rats. Mol Nutr Food Res. 2016;60(5):1090-1098. doi:10.1002/ mnfr.201500667

42. Lei G, Zhang C, Cheng B, Lee C. crossm Supplemental Therapy for Pneumocystis. J Med. 2017;61(10):1-13.

43. Journal E. Global epidemic of coronavirus-COVID-19: what can we do to minimize risks. Eur J Biomed Pharm Sci. 2020;7 (3):432-438.

44. Grad R. Cod and the consumptive: a brief history of cod-liver oil in the treatment of pulmonary tuberculosis. Pharm Hist. 2004;46 (3):106-120.

45. Bikle DD. Vitamin D and immune function: understanding common pathways. Curr Osteoporos Rep. 2009;7(2):58-63. doi:10.1007/s11914-009-0011-6

46. Sigmundsdottir H, Pan J, Debes GF, et al. DCs metabolize sunlight-induced vitamin D3 to "program" $\mathrm{T}$ cell attraction to the epidermal chemokine CCL27. Nat Immunol. 2007;8(3):285-293. doi:10.1038/ni1433

47. Bikle DD, Pillai S, Gee E, Hincenbergs M. Regulation of 1, 25dihydroxyvitamin d production in human keratinocytes by interferon- $\gamma$. Endocrinology. 1989;124(2):655-660. doi:10.1210/endo124-2-655

48. Bikle DD, Pillai S, Gee E, Hincenbergs M. Tumor necrosis factor- $\alpha$ Regulation of 1, 25-Dihydroxy vitamin D production by Human Keratinocytes. Endocrinology. 1991;129(1):33-38. doi:10.1210/endo-129-1-33

49. Medzhitov R. Recognition of microorganisms and activation of the immune response. Nature. 2007;449(7164):819-826. doi:10.1038/nature06246
50. Liu PT, Stenger S, Li H, et al. Toll-like receptor triggering of a vitamin D-mediated human antimicrobial response. Science. 2006;311(5768):1770-1773. doi:10.1126/science.1123933

51. Schauber J, Dorschner RA, Coda AB, et al. Injury enhances TLR2 function and antimicrobial peptide expression through a vitamin D-dependent mechanism. J Clin Invest. 2007;117 (3):803-811. doi:10.1172/JCI30142

52. Rook GA, Steele J, Fraher L, et al. Vitamin D3, gamma interferon, and control of proliferation of Mycobacterium tuberculosis by human monocytes. Immunology. 1986.

53. Cadranel J, Milleron B, Garabedian M, Aroun G. Serum concentrations of vitaniin D metabolites in untreated tuberculosis. Thorax. 1985;40(8):639-640. doi:10.1136/thx.40.8.639-b

54. Ong PY, Ohtake T, Brandt C, et al. Endogenous Antimicrobial Peptides and Skin Infections in Atopic Dermatitis. $N$ Engl J Med. 2002;347(15):1151-1160. doi:10.1056/nejmoa021481

55. Salahuddin N, Ali F, Hasan Z, Rao N, Aqeel M, Mahmood F. Vitamin D accelerates clinical recovery from tuberculosis: results of the SUCCINCT Study [Supplementary Cholecalciferol in recovery from tuberculosis]. A randomized, placebo-controlled, clinical trial of vitamin D supplementation in patients with pulmonar. BMC Infect Dis. 2013;13(1). doi:10.1186/1471-233413-22

56. Tukvadze N, Sanikidze E, Kipiani M, et al. High-dose Vitamin D3 in adults with pulmonary tuberculosis: a double-blind randomized controlled trial. Am J Clin Nutr. 2015;102(5):1059-1069. doi:10.3945/ajen.115.113886

57. Cantorna MT, Snyder L, Lin YD, Yang L. Vitamin D and 1,25 (OH)2D regulation of T cells. Nutrients. 2015;7(4):3011-3021. doi:10.3390/nu7043011

58. Mora JR, Iwata M, Von AUH. Vitamin effects on the immune system. Nat Rev Immunol. 2008;8(9):685-698. doi:10.1038/ nri2378.Vitamin

59. Daniel C, Sartory NA, Zahn N, Radeke HH, Stein JM. Immune modulatory treatment of trinitrobenzene sulfonic acid colitis with calcitriol is associated with a change of a T helper (Th) $1 /$ Th17 to a Th2 and regulatory $\mathrm{T}$ cell profile. $J$ Pharmacol Exp Ther. 2008;324(1):23-33. doi:10.1124/jpet.107.127209

60. Adorini L, Penna G. Dendritic cell tolerogenicity: a key mechanism in immunomodulation by vitamin D receptor agonists. Hum Immunol. 2009;70(5):345-352. doi:10.1016/j. humimm.2009.01.016

61. Overbergh L, Decallonne B, Waer M, et al. Immune Shift in NOD Mice Immunized. Prism. 2014. 65;1l:1301-1307.

62. Veldman CM, Cantorna MT, DeLuca HF. Expression of 1,25-dihydroxyvitamin D3 receptor in the immune system. Arch Biochem Biophys. 2000;374(2):334-338. doi:10.1006/ abbi.1999.1605

63. Babbe H, Roers A, Waisman A, et al. Clonal expansions of CD8+ $\mathrm{T}$ cells dominate the $\mathrm{T}$ cell infiltrate in active multiple sclerosis lesions as shown by micromanipulation and single cell polymerase chain reaction. $J$ Exp Med. 2000;192(3):393-404. doi:10.1084/jem.192.3.393

64. Dall'Ara F, Andreoli L, Piva N, Piantoni S, Franceschini F, Tincani A. Winter lupus flares are associated with low vitamin D levels in a retrospective longitudinal study of Italian adult patients. Clin Exp Rheumatol. 2015;33(2):153-158.

65. Mok CC, Bro ET, Ho LY, Singh RJ, Jannetto PJ. Serum 25-hydroxyvitamin D3 levels and flares of systemic lupus erythematosus: a longitudinal cohort analysis. Clin Rheumatol. 2018;37 (10):2685-2692. doi:10.1007/s10067-018-4204-1

66. Buondonno I, Rovera G, Sassi F, et al. Vitamin D and immunomodulation in early rheumatoid arthritis: a randomized doubleblind placebo-controlled study. PLoS One. 2017;12(6):1-18. doi:10.1371/journal.pone. 0178463 
67. Chen S, Sims GP, Chen XX, Gu YY, Chen S, Lipsky PE. Modulatory Effects of 1,25-Dihydroxyvitamin D 3 on Human B Cell Differentiation. J Immunol. 2007;179(3):1634-1647. doi:10.4049/jimmunol.179.3.1634

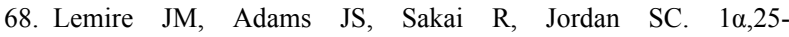
Dihydroxyvitamin D3 suppresses proliferation and immunoglobulin production by normal human peripheral blood mononuclear cells. J Clin Invest. 1984;74(2):657-661. doi:10.1172/JCI111465

69. Iho S, Takahashi T, Kura F, Sugiyama H, Hoshino T. The effect of 1,25-dihydroxyvitamin $\mathrm{D} 3$ on in vitro immunoglobulin production in human B cells. J Immunol. 1986;136(12):4427-4431.

70. Biesalski HK. Vitamin D deficiency and co-morbidities in COVID-19 patients - a fatal relationship? NFS J. 2020 doi:10.1016/j.nfs.2020.06.001

71. Hackenthal E, Paul M, Ganten D, Taugner R. Morphology, physiology, and molecular biology of renin secretion. Physiol Rev. 1990;70(4):1067-1116. doi:10.1152/physrev.1990.70.4.1067

72. Ocaranza MP, Lavandero S, Jalil JE, et al. Angiotensin-(1-9) regulates cardiac hypertrophy in vivo and in vitro. $J$ Hypertens. 2010;28(5):1054-1064. doi:10.1097/HJH.0b013e328335d291

73. Tomaschitz A, Pilz S, Ritz E, et al. Independent association between 1,25-dihydroxyvitamin D, 25-hydroxyvitamin $\mathrm{D}$ and the renin-angiotensin system. The Ludwigshafen Risk and Cardiovascular Health (LURIC) study. Clin Chim Acta. 2010;411(17-18):1354-1360. doi:10.1016/j.cca.2010.05.037

74. Vaidya A, Forman JP, Hopkins PN, Seely EW, Williams JS. 25Hydroxyvitamin D is associated with plasma renin activity and the pressor response to dietary sodium intake in Caucasians. JRAAS. 2011;12(3):311-319. doi:10.1177/1470320310391922

75. Burgess ED, Hawkins RG, Watanabe M. Interaction of 1,25-dihydroxyvitamin $\mathrm{d}$ and plasma renin activity in high renin essential hypertension. Am $J$ Hypertens. 1990;3 (12_Pt_1):903-905. doi:10.1093/ajh/3.12.903

76. Li YC, Qiao G, Uskokovic M, Xiang W, Zheng W, Kong J. Vitamin D: a negative endocrine regulator of the renin-angiotensin system and blood pressure. J Steroid Biochem Mol Biol. 2004;89-90:387-392. doi:10.1016/j.jsbmb.2004.03.004

77. Yuan W, Pan W, Kong J, et al. 1,25-Dihydroxyvitamin D3 suppresses renin gene transcription by blocking the activity of the cyclic AMP response element in the renin gene promoter. $J$ Biol Chem. 2007;282(41):29821-29830. doi:10.1074/jbc.M705495200

78. Cui C, Xu P, Li G, et al. Vitamin D receptor activation regulates microglia polarization and oxidative stress in spontaneously hypertensive rats and angiotensin II-exposed microglial cells: role of renin-angiotensin system. Redox Biol. 2019;26:101295. doi:10.1016/j.redox.2019.101295

79. Cohen-Lahav M, Shany S, Tobvin D, Chaimovitz C, Douvdevani A. Vitamin D decreases NFkB activity by increasing IкB $\alpha$ levels. Nephrol Dial Transplant. 2006;21(4):889-897. doi:10.1093/ndt/gfi254

80. Schroten NF, Ruifrok WPT, Kleijn L, et al. Short-term vitamin D3 supplementation lowers plasma renin activity in patients with stable chronic heart failure: an open-label, blinded end point, randomized prospective trial (VitD-CHF trial). Am Heart $J$. 2013;166(2):357-364.e2. doi:10.1016/j.ahj.2013.05.009

81. Forman JP, Williams JS, Fisher NDL. Plasma 25-hydroxyvitamin $\mathrm{D}$ and regulation of the renin-angiotensin system in humans. Hypertension. 2010;55(5):1283-1288. doi:10.1161/ HYPERTENSIONAHA.109.148619

82. Zittermann A, Ernst JB, Prokop S, et al. Effects of Vitamin D Supplementation on Renin and Aldosterone Concentrations in Patients with Advanced Heart Failure: the EVITA Trial. Int J Endocrinol. 2018;2018:1-10. doi:10.1155/2018/5015417

83. Hong JY, Kim SY, Chung KS, et al. Association between vitamin $\mathrm{D}$ deficiency and tuberculosis in a Korean population. Int $J$ Tuberc Lung Dis. 2014;18(1):73-78. doi:10.5588/ijtld.13.0536
84. Prietl B, Treiber G, Pieber TR, Amrein K. Vitamin D and immune function. Nutrients. 2013;5(7):2502-2521. doi:10.3390/ nu5072502

85. De Caterina R, Alfredo Martinez J, Kohlmeier M. Principles of Nutrigenetics and Nutrigenomics: fundamentals for Individualized Nutrition. Discov Med. 2019. doi:10.1016/C20150-01839-1

86. Daneshkhah A, Agrawal V, Eshein A, Subramanian H, Roy HK, Backman V. Evidence for possible association of vitamin D status with cytokine storm and unregulated inflammation in COVID-19 patients. Aging Clin Exp Res. 2020;32(10):2141-2158. doi:10.1007/s40520-020-01677-y

87. Mangin M, Sinha R, Fincher K. Inflammation and vitamin D: the infection connection. Inflamm Res. 2014;63(10):803-819. doi:10.1007/s00011-014-0755-Z

88. Schleithoff SS, Zittermann A, Tenderich G, Berthold HK, Stehle P, Koerfer R. Vitamin D supplementation improves cytokine profiles in patients with congestive heart failure: a double-blind, randomized, placebo-controlled trial. Am J Clin Nutr. 2006;83(4):754-759. doi:10.1093/ajcn/83.4.754

89. Wu S, Sun J. Vitamin D, vitamin D receptor, and macroautophagy in inflammation and infection. Discov Med. 2011;11(59):325-335.

90. Martineau AR, Wilkinson RJ, Wilkinson KA, et al. A single dose of vitamin D enhances immunity to mycobacteria. Am J Respir Crit Care Med. 2007;176(2):208-213. doi:10.1164/rccm.200701$007 \mathrm{OC}$

91. Li G, Fan Y, Lai Y, et al. Coronavirus infections and immune responses. J Med Virol. 2020;92(4):424-432. doi:10.1002/ jmv. 25685

92. Kenneth Weir E, Thenappan T, Bhargava M, Chen Y. Does Vitamin D deficiency increase the severity of COVID-19? Clin Med $J \quad R$ Coll Physicians London. 2020. doi:10.7861/ CLINMED.2020-0301

93. Beristain-Covarrubias N, Perez-Toledo M, Thomas MR, Henderson IR, Watson SP, Cunningham AF. Understanding Infection-Induced Thrombosis: lessons Learned From Animal Models. Front Immunol. 2019;10. doi:10.3389/fimmu.2019.02569

94. Dehghani K, Nowrouzi A, Hossein Pourdavood A, Rahmanian Z. Effect of Vitamin D deficiency in lower extremity and pulmonary venous thromboembolism. Biomed Res Ther. 2019;6 (4):3107-3112. doi:10.15419/bmrat.v6i4.535

95. Corrales-Medina VF, Madjid M, Musher DM. Role of acute infection in triggering acute coronary syndromes. Lancet Infect Dis. 2010;10(2):83-92. doi:10.1016/S1473-3099(09)70331-7

96. Mohammad S, Mishra A, Ashraf MZ. Emerging role of vitamin $\mathrm{d}$ and its associated molecules in pathways related to pathogenesis of thrombosis. Biomolecules. 2019;9(11):649. doi:10.3390/ biom9110649

97. LaCroix AZ, Kotchen J, Anderson G, et al. Calcium plus vitamin D supplementation and mortality in postmenopausal women: the women's health initiative calcium-vitamin D randomized controlled trial. J Gerontol. 2009;64A(5):559-567. doi:10.1093/gerona/glp006

98. Rhodes JM, Subramanian S, Laird E, Griffin G, Kenny RA Perspective: vitamin D Deficiency and COVID-19 Severity plausibly Linked by Latitude, Ethnicity, Impacts on Cytokines, ACE2 and Thrombosis. Journal of Internal Medicine. 2020;289 (1):97-115. doi:10.1111/joim.13149

99. Ishigami J, Kou M, Ding N, Matsushita K. Cardiovascular Disease and Coronavirus Disease 2019: epidemiology, Management, and Prevention. Curr Epidemiol Reports. 2021;8 (1):1-8. doi:10.1007/s40471-020-00261-2

100. Mitchell F. Vitamin-D and COVID-19: do deficient risk a poorer outcome? Lancet Diabetes Endocrinol. 2020;8(7):570. doi:10.1016/S2213-8587(20)30183-2 
101. Banerjee A, Khemka VK. Augmentation of anticoagulant effect with vitamin D: possible therapeutic target for venous thromboembolism. Int J Hematol Blood Disord. 2017;2(1):1-5. doi:10.15226/2639-7986/2/1/00106

102. McMullan CJ, Borgi L, Curhan GC, Fisher N, Forman JP. The effect of Vitamin D on renin-angiotensin system activation and blood pressure: a randomized control trial. J Hypertens. 2016;35 (4):822-829. doi:10.1097/HJH.0000000000001220

103. Sundaram ME, Coleman LA. Vitamin D and In fl uenza. Advances in Nutrition (Bethesda, Md.). 2012;3(4):517-525. doi:10.3945/an.112.002162.Current

104. Urashima M, Segawa T, Okazaki M, Kurihara M, Wada Y, Ida H. Randomized trial of vitamin D supplementation to prevent seasonal influenza A in schoolchildren. Am J Clin Nutr. 2010;91 (5):1255-1260. doi:10.3945/ajcn.2009.29094

105. Martineau AR, Jolliffe DA, Hooper RL, et al. Vitamin $\mathrm{D}$ supplementation to prevent acute respiratory tract infections: systematic review and meta-analysis of individual participant data. BMJ. 2017;356:356. doi:10.1136/bmj.i6583

106. Cannell JJ, Vieth R, Umhau JC, et al. Epidemic influenza and vitamin D. Epidemiol Infect. 2006;134(6):1129-1140. doi:10.1017/S0950268806007175

107. Cannell JJ, Zasloff M, Garland CF, Scragg R, Giovannucci E. On the epidemiology of influenza. Virol J. 2008;5(1):29. doi:10.1186/ 1743-422X-5-29

108. Vieth R. Vitamin D supplementation, 25-hydroxyvitamin D concentrations, and safety. Am J Clin Nutr. 1999;69 (5):842-856. doi:10.1093/ajcn/69.5.842

109. World Health Organization. 2020 W. Global Tuberculosis Report 2020. J Chem Inf Model. 2020.

110. Zhai W, Wu F, Zhang Y, Fu Y, Liu Z. The immune escape mechanisms of Mycobacterium Tuberculosis. Int J Mol Sci. 2019;20(2):2. doi:10.3390/ijms20020340

111. Sia JK, Rengarajan J. Immunology of mycobacterium tuberculosis infections. Gram-Positive Pathog. 2019;1056-1086. doi:10.1128/9781683670131.ch64

112. Mily A, Rekha RS, Kamal SMM, et al. Significant effects of oral phenylbutyrate and Vitamin D3 adjunctive therapy in pulmonary tuberculosis: a randomized controlled trial. PLoS One. 2015;10 (9):1-25. doi:10.1371/journal.pone.0138340

113. Tyagi G, Singh P, Varma-Basil M, Bose M. Role of Vitamins B, $\mathrm{C}$, and $\mathrm{D}$ in the fight against tuberculosis. Int J Mycobacteriology. 2017. doi:10.4103/ijmy.ijmy_80_17

114. Nnoaham KE, Clarke A. Low serum vitamin D levels and tuberculosis: a systematic review and meta-analysis. Int $J$ Epidemiol. 2008;37(1):113-119. doi:10.1093/ije/dym247

115. Zhang Y, Zhu H, Yang X, et al. Serum Vitamin D level and Vitamin D receptor genotypes may be associated with tuberculosis clinical characteristics A case-control study. Med. 2018. doi:10.1097/MD.0000000000011732

116. Ayelign B, Workneh M, Molla MD, Dessie G. Role of vitamin-D supplementation in TB/HIV co-infected patients. Infect Drug Resist. 2020; Volume 13:111-118. doi:10.2147/IDR.S228336

117. Talat N, Perry S, Parsonnet J, Dawood G, Hussain R. Vitamin $\mathrm{D}$ deficiency and tuberculosis progression. Emerg Infect Dis. 2010;16(5):853-855. doi:10.3201/eid1605.091693

118. Gou X, Pan L, Tang F, Gao H, Xiao D. The association between Vitamin D status and tuberculosis in children: a meta-analysis. Med. 2018. doi:10.1097/MD.0000000000012179

119. Aibana O, Huang CC, Aboud S, et al. Vitamin D status and risk of incident tuberculosis disease: a nested case-control study, systematic review, and individualparticipant data meta-analysis. PLoS Med. 2019;16(9):1-26. doi:10.1371/journal.pmed.1002907
120. Michos ED. Vitamin D deficiency and the risk of tuberculosis: a meta-analysis. Future Cardiol. 2009;5(1):15-18. doi:10.2217/ 14796678.5.1.15

121. Ganmaa D, Initiative MH, Uyanga B, et al. HHS Public Access. Nutr Rev. 2021;383(4):359-368. DOI:10.1056/NEJMoa1915176.Vitamin

122. Brighenti S, Bergman P, Martineau AR. Vitamin D and tuberculosis: where next? J Intern Med. 2018;284(2):145-162. doi:10.1111/joim. 12777

123. Ralph AP, Waramori G, Pontororing GJ, et al. L-arginine and Vitamin D Adjunctive Therapies in Pulmonary Tuberculosis: a Randomised, Double-Blind, Placebo-Controlled Trial. PLoS One. 2013;8(8):e70032. doi:10.1371/journal.pone.0070032

124. Mansueto P, Seidita A, Vitale G, Gangemi S, Iaria C, Cascio A. Vitamin D deficiency in HIV infection: not only a bone disorder. Biomed Res Int. 2015;2015:1-18. doi:10.1155/2015/735615

125. Deeks SG. Systemic Effects of Inflammation on Health during Chronic. Infection. 2014;39(4):633-645. doi:10.1016/j. immuni.2013.10.001.Systemic

126. Villamor E. A potential role for vitamin D on HIV infection? Nutr Rev. 2006;64(5):226-233. doi:10.1301/nr.2006.may.226-233

127. Röling J, Schmid H, Fischereder M, Draenert R, Goebel FD. HIV-associated renal diseases and highly active antiretroviral therapy-induced nephropathy. Clin Infect Dis. 2006;42 (10):1488-1495. doi:10.1086/503566

128. Mehta S, Mugusi FM, Spiegelman D, et al. Vitamin D status and its association with morbidity including wasting and opportunistic illnesses in HIV-infected women in Tanzania. AIDS Patient Care STDS. 2011;25(10):579-585. doi:10.1089/apc.2011.0182

129. Von Essen MR, Kongsbak M, Schjerling P, Olgaard K, Ødum N, Geisler C. Vitamin D controls $\mathrm{T}$ cell antigen receptor signaling and activation of human T cells. Nat Immunol. 2010;11 (4):344-349. doi:10.1038/ni.1851

130. Haug CJ, Müller F, Aukrust P, Frøland SS. Different effect of 1,25-dihydroxyvitamin D3 on replication of Mycobacterium avium in monocyte-derived macrophages from human immunodeficiency virus-infected subjects and healthy controls. Immunol Lett. 1998;63(2):107-112. doi:10.1016/S0165-2478(98)00065-0

131. Aguilar-Jimenez W, Villegas-Ospina S, Gonzalez S, et al. Precursor forms of Vitamin D reduce HIV-1 infection in vitro. J Acquir Immune Defic Syndr. 2016;73(5):497-506. doi:10.1097/ QAI.0000000000001150

132. Viard JP, Souberbielle JC, Kirk O, et al. Vitamin D and clinical disease progression in HIV infection: results from the EuroSIDA study. Aids. 2011;25(10):1305-1315. doi:10.1097/QAD.0b013e328347f6f7

133. Aziz M, Livak B, Burke-Miller J, et al. Vitamin D insufficiency may impair CD4 recovery among Women's Interagency HIV Study participants with advanced disease on HAART. Aids. 2013;27(4):573-578. doi:10.1097/QAD.0b013e32835b9ba1

134. Haug C, Müller F, Aukrust P, Frøland SS. Subnormal serum concentration of 1, 25-vitamin d in human immunodeficiency virus infection: correlation with degree of immune deficiency and survival. J Infect Dis. 1994;169(4):889-893. doi:10.1093/infdis/169.4.889

135. Baker JV, Peng G, Rapkin J, et al. CD4+ count and risk of non-AIDS diseases following initial treatment for HIV infection. Aids. 2008;22(7):841-848. doi:10.1097/QAD.0b013e3282f7cb76

136. Jiménez-Sousa M, Martínez I, Medrano LM, FernándezRodríguez A, Resino S. Vitamin D in human immunodeficiency virus infection: influence on immunity and disease. Front Immunol. 2018;9(MAR). doi:10.3389/fimmu.2018.00458

137. Tenforde MW, Yadav A, Dowdy DW, et al. Vitamin A and D Deficiencies Associated with Incident Tuberculosis in HIV-Infected Patients Initiating Antiretroviral Therapy in Multinational Case-Cohort Study. J Acquir Immune Defic Syndr. 2017;75(3):e71-e79. doi:10.1097/QAI.0000000000001308 
138. Coelho L, Cardoso SW, Luz PM, et al. Vitamin D3 supplementation in HIV infection: effectiveness and associations with antiretroviral therapy. Nutr J. 2015;14(1):1-9. doi:10.1186/s12937-0150072-6

139. Dougherty KA, Schall JI, Zemel BS, et al. Safety and efficacy of high-dose daily vitamin D3 supplementation in children and young adults infected with human immunodeficiency virus. J Pediatric Infect Dis Soc. 2014;3(4):294-303. doi:10.1093/ jpids/piu012

140. WHO. WHO Director-General's opening remarks at the media briefing on COVID-19 - March 2020 - World | reliefWeb. 2020. Available from: https://reliefweb.int/report/world/who-directorgenerals-opening-remarks-media-briefing-covid-19-4-december2020. Accessed February 25, 2021.

141. Cucinotta D, Vanelli M. WHO declares COVID-19 a pandemic. Acta Biomed. 2020;91(1):157-160. doi:10.23750/abm.v91i1.9397

142. Peiris JSM, Guan Y, Yuen KY. Severe acute respiratory syndrome. Nat Med. 2004;10(12S):S88-S97. doi:10.1038/nm1143

143. Huang C, Wang Y, Li X, et al. Clinical features of patients infected with 2019 novel coronavirus in Wuhan, China. Lancet. 2020;395(10223):497-506. doi:10.1016/S0140-6736(20)30183-5

144. Xu Z, Shi L, Wang Y, et al. Pathological findings of COVID-19 associated with acute respiratory distress syndrome. Lancet Respir Med. 2020;8(4):420-422. doi:10.1016/S2213-2600(20) 30076-X

145. Chan JFW, Yuan S, Kok KH, et al. A familial cluster of pneumonia associated with the 2019 novel coronavirus indicating person-to-person transmission: a study of a family cluster. Lancet. 2020;395(10223):514-523. doi:10.1016/S0140-6736(20) 30154-9

146. Middeldorp S, Coppens M, van Haaps TF, et al. Incidence of venous thromboembolism in hospitalized patients with COVID-19. $J$ Thromb Haemost. 2020;18(8):1995-2002. doi:10.1111/jth. 14888

147. Ahmed M, Sultana M. COVID-19 Pneumonia Complicated by Acute Pulmonary Embolism. J Bangladesh Coll Physicians Surg. 2020;82-83. doi:10.3329/jbcps.v38i0.47348

148. Sungnak W, Huang N, Bécavin C, et al. SARS-CoV-2 entry factors are highly expressed in nasal epithelial cells together with innate immune genes. Nat Med. 2020;26(5):681-687. doi:10.1038/s41591-020-0868-6

149. Kokubu T, Takada Y. Angiotensin converting enzyme. Nippon Rinsho Japanese J Clin Med. 1982;40(9):1956-1963. doi:10.1161/circulationaha.120.047049

150. Coperchini F, Chiovato L, Croce L, Magri F, Rotondi M. ThecytokinestorminCOVID-19:

Anoverviewoftheinvolvementofthechemokine/chemokinereceptorsyste. Cytokine Growth Factor Rev. 2020;53:25-32. doi:10.1016/j.cytogfr.2020.05.003

151. Channappanavar R, Perlman S. Pathogenic human coronavirus infections: causes and consequences of cytokine storm and immunopathology. Semin Immunopathol. 2017;39(5):529-539. doi:10.1007/s00281-017-0629-x

152. Clerkin KJ, Fried JA, Raikhelkar J, et al. COVID-19 and Cardiovascular Disease. Circulation. 2020;2019:1648-1655. doi:10.1161/CIRCULATIONAHA.120.046941

153. Li X, Geng M, Peng Y, Meng L, Lu S. Molecular immune pathogenesis and diagnosis of COVID-19. J Pharm Anal. 2020;10(2):102-108. doi:10.1016/j.jpha.2020.03.001

154. Liu J, Wu P, Gao F, et al. Novel Immunodominant Peptide Presentation Strategy: a Featured HLA-A*2402-Restricted Cytotoxic T-Lymphocyte Epitope Stabilized by Intrachain Hydrogen Bonds from Severe Acute Respiratory Syndrome Coronavirus Nucleocapsid Protein. $J$ Virol. 2010;84 (22):11849-11857. doi:10.1128/jvi.01464-10
155. Jeffery LE, Burke F, Mura M, et al. 1,25-Dihydroxyvitamin D 3 and IL-2 Combine to Inhibit T Cell Production of Inflammatory Cytokines and Promote Development of Regulatory $\mathrm{T}$ Cells Expressing CTLA-4 and FoxP3. $J$ Immunol. 2009;183 (9):5458-5467. doi:10.4049/jimmunol.0803217

156. Dimitrov V, White JH. Species-specific regulation of innate immunity by vitamin D signaling. $J$ Steroid Biochem Mol Biol. 2016;164:246-253. doi:10.1016/j.jsbmb.2015.09.016

157. Snijder EJ, van der Meer Y, Zevenhoven-Dobbe J, et al. Ultrastructure and Origin of Membrane Vesicles Associated with the Severe Acute Respiratory Syndrome Coronavirus Replication Complex. J Virol. 2006;80(12):5927-5940. doi:10.1128/jvi.02501-05

158. Blanco-Melo D, Nilsson-Payant BE, Liu WC, et al. Imbalanced Host Response to SARS-CoV-2 Drives Development of COVID-19. Cell. 2020;181(5):1036-1045.e9. doi:10.1016/j.cell.2020.04.026

159. Hadjadj J, Yatim N, Barnabei L, et al. Impaired type I interferon activity and inflammatory responses in severe COVID-19 patients. Science. 2020.

160. Murdaca G, Pioggia G, Negrini S. Vitamin D and Covid-19: an update on evidence and potential therapeutic implications. Clin Mol Allergy. 2020;18(1):1-8. doi:10.1186/s12948-020-00139-0

161. Kakodkar P, Kaka N, Baig M, Comprehensive Literature A. Review on the Clinical Presentation, and Management of the Pandemic Coronavirus Disease 2019 (COVID-19). Cureus. 2020;2019(4). doi:10.7759/cureus.7560

162. Zhang J, McCullough PA, Tecson KM. Vitamin D deficiency in association with endothelial dysfunction: implications for patients with COVID-19. Rev Cardiovasc Med. 2020;21(3):339-344. doi:10.31083/j.rcm.2020.03.131

163. Carter SJ, Baranauskas MN, Fly AD. Considerations for Obesity, Vitamin D, and Physical Activity Amid the COVID-19 Pandemic. Obesity. 2020;28(7):1176-1177. doi:10.1002/oby.22838

164. La Vignera S, Cannarella R, Condorelli RA, Torre F, Aversa A, Calogero AE. Sex-specific SARS-CoV2 mortality: among hormone-modulated ace 2 expression, risk of venous thromboembolism and hypovitaminosis D. Int J Mol Sci. 2020;21(8):5-10. doi:10.3390/ijms21082948

165. Raharusuna P, Priambada S, Budiarti C, Agung E, Budi C. Patterns of mortality and vitamin D: an Indonesian study. Preprint. 2020.

166. Tian Y, Rong L. Letter: covid-19, and vitamin D. Authors' reply. Aliment Pharmacol Ther. 2020;51(10):995-996. doi:10.1111/ apt.15764

167. Xu J, Yang J, Chen J, Luo Q, Zhang Q, Zhang H. Vitamin $\mathrm{D}$ alleviates lipopolysaccharide-induced acute lung injury via regulation of the renin-angiotensin system. Mol Med Rep. 2017. doi:10.3892/mmr.2017.7546

168. Grant WB, Lahore H, McDonnell SL, et al. Vitamin D Supplementation Could Prevent and Treat Influenza, Coronavirus, and Pneumonia Infections. Preprints. 2020.

169. Alipio M. Vitamin D Supplementation Could Possibly Improve Clinical Outcomes of Patients Infected with Coronavirus-2019 (COVID-2019). SSRN Electron J. 2020. doi:10.2139/ssrn.3571484

170. Murai IH, Fernandes AL, Sales LP, et al. Effect of a Single High Dose of Vitamin D3on Hospital Length of Stay in Patients with Moderate to Severe COVID-19: a Randomized Clinical Trial. JAMA. 2021;325(11):1053-1060. doi:10.1001/jama.2020.26848

171. Cascella M, Rajnik M, Cuomo A, Dulebohn SC, Di Napoli R. Features, Evaluation and Treatment Coronavirus (COVID-19). StatPearls. 2020.

172. Cortegiani A, Ingoglia G, Ippolito M, Giarratano A, Einav S. Since January 2020 Elsevier has created a COVID-19 resource centre with free information in English and Mandarin on the novel coronavirus COVID- 19. The COVID-19 resource centre is hosted on Elsevier Connect, the company's public news and information. $J$ Crit Care. 2020;57(January):279-283. doi:10.1016/j.jcrc.2020.03.005 
173. Xu X, Han M, Li T, et al. Effective treatment of severe COVID-19 patients with tocilizumab. Proc Natl Acad Sci U S A. 2020;117 (20):10970-10975. doi:10.1073/pnas.2005615117

174. Zhang R, Wang X, Ni L, et al. COVID-19: melatonin as a potential adjuvant treatment. Life Sciences. 2020;250:117583. doi:10.1016/j.1fs.2020.117583

175. Jean -S-S, Lee P-I, Hsueh P-R. Treatment options for COVID-19: the reality and challenges. J Microbiol Immunol Infect. 2020;53 (3):436. doi:10.1016/j.jmii.2020.03.034

176. Şimşek Yavuz S, Ünal S. Antiviral treatment of covid-19. Turkish J Med Sci. 2020;50(SI-1):611-619. doi:10.3906/sag2004-145
177. Gautret P, Lagier J, Parola P, Hoang VT, Hydroxychloroquine and azithromycin as a treatment of COVID-19: results of an open-label non-randomized clinical trial. Int J Antimicrob Agents. 2020;56 (1):105949. doi:10.1016/j.ijantimicag.2020.105949

178. Geleris J, Sun Y, Platt J, et al. Observational Study of Hydroxychloroquine in Hospitalized Patients with Covid-19. $N$ Engl $J$ Med. 2020;382(25):2411-2418. doi:10.1056/nejmoa2012410

179. Roth A, Lütke S, Meinberger D, et al. LL-37 fights SARS-CoV-2: the vitamin D-Inducible peptide LL-37 inhibits binding of SARS-CoV-2 spike protein to its cellular receptor angiotensin converting enzyme 2 in Vitro. bioRxiv. 2020. doi:10.1101/ 2020.12.02.408153

\section{Publish your work in this journal}

The International Journal of General Medicine is an international, peer-reviewed open-access journal that focuses on general and internal medicine, pathogenesis, epidemiology, diagnosis, monitoring and treatment protocols. The journal is characterized by the rapid reporting of reviews, original research and clinical studies across all disease areas. The manuscript management system is completely online and includes a very quick and fair peer-review system, which is all easy to use. Visit http://www.dovepress.com/ testimonials.php to read real quotes from published authors. 